Stockholms

universitet

Psykologiska Institutionen

\title{
Mental health literacy about depression and schizophrenia among Swedish teenagers: a vignette study
}

Author: Evaggelia Tartani

Main Supervisor: Yvonne Forsell

Co-Supervisor: Philippe A. Melas

Examiner: Christine Mellner

MASTER'S THESIS IN PSYCHOLOGY, 30 CREDITS, 2011 


\section{ACKNOWLEDGEMENTS}

I would like to thank some people that made this study possible.

First, I would like to acknowledge the Australasian Medical Publishing Company for the permissions granted with regard to the reuse of the vignettes used in this study: "Jorm AF et al. "Mental health literacy": a survey of the public's ability to recognize mental disorders and their beliefs about the effectiveness of treatment. MJA 1997; 166: 182 - 186. Copyright 1997. The Medical Journal of Australia reproduced with permission"

A particular acknowledgment goes to Sofia Kourtidou for supporting me in every way possible throughout my study period.

I would also like to thank my parents for being so supportive and respectful to me; even though I moved to another country, I felt them closer than ever.

And last but not least, I want to express my gratitude to my supervisors, Yvonne Forsell and Philippe A. Melas, for the time to supervise this master thesis and their valuable advice. And, of course, I also thank all the students who participated in this study and made it possible.

Evaggelia Tartani, Stockholm, May 2011 
Table of Contents

ACKNOWLEDGEMENTS

ABSTRACT

INTRODUCTION.

i. In General

ii. Background

a. Mental disorders

b. Depression

c. Schizophrenia

d. Mental health literacy

e. Adolescents' mental health literacy and help seeking behavior

f. Altruism

g. Stigma related to mental disorders

iii. Literature Overview

iv. Rationale of the Present Study

a. Purpose

b. Research Questions

STUDY DESIGN AND METHODOLOGY

i. Design

ii. Participants and data collection process

iii. The vignette

iv. Data analysis

v. Ethical and copyright considerations

RESULTS..........................................................................
A. Mental health literacy about depression
B. Forms of helping a friend with schizophrenia
C. Mental health literacy about schizophrenia
D. Forms of helping a friend with schizophrenia
E. Forms of helping a peer with depression or schizophrenia
F. Stigma and attitudes towards schizophrenic symptoms

Choice of research method

Choice of method when collecting the data

Validity

Discussion of results

Limitations of the study

Study's practical implications

Future research 
LIST OF REFERENCES................................................ 46

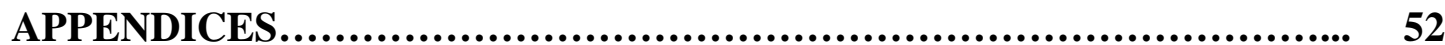

Appendix 1- Information to the teacher/mentor

Appendix 2- Vignette

Appendix 3- Answers sheets

Appendix 4-Tables 


\title{
MENTAL HEALTH LITERACY ABOUT DEPRESSION AND SCHIZOPHRENIA AMONG SWEDISH TEENAGERS: A VIGNETTE STUDY
}

\author{
Evaggelia Tartani
}

\begin{abstract}
Although the prevalence of mental pathology is high, public's mental health literacy (i.e. knowledge about mental disorders) has not been examined to a great extent. The main purpose of this study was to examine mental health literacy concerning depression and schizophrenia in a setting of adolescents in Sweden. A secondary aim was to explore stigmatizing attitudes towards mentally ill and levels of altruism among adolescents regarding help-seeking behavior. The present study employed qualitative methodology and data were collected through vignettes. A total of 426 high school students living in Stockholm formed the respondents and content analysis showed that among teenagers recognition of both depression and schizophrenia was poor. Moreover, friends and informal sources of help were regarded as best types of help. Furthermore, results indicated stigmatizing beliefs about mental disorders and low levels of altruistic behavior. These results are supported from other similar studies and suggest awareness campaigns to increase mental health literacy among adolescents. Recommendations for future research are also discussed.
\end{abstract}

Keywords: mental health literacy, depression, schizophrenia, altruism, stigma, adolescents, knowledge 


\section{INTRODUCTION}

\section{i. In General}

It is estimated that over $4.5 \%$ of the population worldwide suffer from depression and $1 \%$ of schizophrenia (WHO, 2007). These two mental illnesses are both associated with suicidal behavior. In particular, there is a high prevalence of suicide in schizophrenics (10\%) and the suicides attributed to depression in 2005 were $1.4 \%$ of all deaths worldwide (Evidensbaserad omvårdnad - Behandling av personer med schizofreni, 2009).

One of the main problems for the treatment of psychiatric disorders is that people cannot recognize them most of the times. People seem to be more informed about physical problems and seek help more easily for those than about mental health problems. It has been found that the knowledge and the attitudes held by society and health care workers concerning depression and schizophrenia affect to a great extent depressed and schizophrenic people’s prognosis (Evidensbaserad omårdnad , behandling av personer med schizofreni, 2009). Taking into account the fact that early interventions is related to improved long term outcomes (Manos, 1997) it is a matter of major concern that up to $70 \%$ mentally ill do not seek help (Farrer, Leach, Griffiths, Christensen \& Jorm, 2008). It has been assumed that people's reluctance to seek treatment is due to mental pathology not being considered a medical condition and moreover, due to prejudices against this kind of pathology (Heginbotham, 1998, referred to Canadian alliance on mental illness and mental health, 2004). There are many studies confirming the assumptions that poor mental health literacy impedes appropriate and early help seeking (Burke, Burke, Regier \& Rae, 1990; Jorm, 2000). This is why it is important to explore levels of mental health literacy but also the willingness to help a peer in need.

\section{ii. Background}

\section{a. Mental disorders}

The term 'mental disorder' refers "collectively to all mental disorders, which are health conditions characterized by alterations in thinking, mood, or behavior (or some combination thereof) associated with distress and/or impaired functioning."( p. 7, U.S. Department of Health and Human Services, 2001). Mental disorders range from mild to severe and are medical conditions meeting certain criteria (most commonly used classification tools are DSM and ICD-10). Mental pathology is not so rare as it is believed to be and almost one quarter of the population is affected at some point throughout life (WHO, 2001).

The way that people perceive mental health problems and treatment is influenced by social and environmental conditions (Canadian alliance on mental illness and mental health, 2004). This means that all cultures recognize the existence of mental disorders but in every culture they are interpreted and treated differently. Jorm et al. (2000) 
stated that people's underlying beliefs about mental pathology affect their attitudes to treatment.

No specific cause of mental disorder has been found and it is thought that a variety of factors (social, psychological and biological) interact and lead to the onset. There are many effective treatments for mental disorders nowadays (medicines, psychotherapy, self help groups etc.) and it is important for people to be aware of that. Two major disabling mental disorders are major depression and schizophrenia.

\section{b. Depression}

Depression is a mental disorder that has various symptoms and is not always easily recognized. This is because depression's most characteristic symptom, i.e. depressed mood, isn't always present. However, there are other symptoms not so well known which can help us recognize this condition. The diagnostic criteria for depression are:

Five (or more) of the following symptoms have been present during the same 2-week period and represent a change from previous functioning; at least one of the symptoms is either (1) depressed mood or (2) loss of interest or pleasure.

- $\quad$ Depressed mood most of the day, nearly every day, as indicated by either subjective report (e.g., feels sad or empty) or observation made by others (e.g., appears tearful). (In children and adolescents, this may be characterized as an irritable mood.)

- $\quad$ Markedly diminished interest or pleasure in all, or almost all, activities most of the day, nearly every day

- $\quad$ Significant weight loss when not dieting or weight gain (e.g., a change of more than 5 of body weight in a month), or decrease or increase in appetite nearly every day.

- Insomnia or hypersomnia nearly every day

- $\quad$ Psychomotor agitation or retardation nearly every day

- $\quad$ Fatigue or loss of energy nearly every day

- $\quad$ Feelings of worthlessness or excessive or inappropriate guilt nearly every day

- $\quad$ Diminished ability to think or concentrate, or indecisiveness, nearly every day

- $\quad$ Recurrent thoughts of death (not just fear of dying), recurrent suicidal ideation without a specific plan, or a suicide attempt or a specific plan for committing suicide

(DSM-IV, 1994).

\section{c. Schizophrenia}

E. Bleuler gave schizophrenia its name, earlier called 'dementia praecox' and it is a psychotic illness that usually manifests in late teens and early adulthood (Manos, 1997).This mental disorder is characterized by loss of contact with reality making it difficult to distinguish real from imaginary. Symptoms of schizophrenia according to DSM -IV (1994) are the following:

Two (or more) of the following, each present for a significant portion of time during a 1-month period (or less if successfully treated): 
- delusions

- hallucinations

- disorganized speech (e.g., frequent derailment or incoherence)

- grossly disorganized or catatonic behavior

- negative symptoms, i.e. affective flattening, alogia, or avolition

\section{d. Mental health literacy}

The high prevalence of mental disorders, 450 million people worldwide suffer from a mental problem (WHO, 2004), makes studying mental health literacy a key issue. There are several definitions of the term 'mental health literacy'. This term was first introduced in 1997, by a study entitled: "Mental health literacy: a survey of the public's ability to recognize mental disorders and their beliefs about the effectiveness of treatment” (Jorm et al., 1997). In this article mental health literacy was defined as:

"knowledge and beliefs about mental disorders which aid their recognition, management or prevention. Mental health literacy includes the ability to recognize specific disorders; knowing how to seek mental health information; knowledge of risk factors and causes, of self-treatments, and of professional help available; and attitudes that promote recognition and appropriate helpseeking” (p. 182).

The term mental health literacy derived from another term called 'health literacy' which is defined as "the ability to gain access to, understand, and use information in ways which promote and maintain good health" (Nutbeam, Wise, Bauman et al., 1993, referred to Jorm et al., 1997). Health literacy is for example people's capacity to understand health related information (Canadian alliance on mental illness and mental health, 2004). Public's mental health literacy "is often assessed in terms of how closely public knowledge and beliefs mirror professional knowledge and beliefs" (p. 4, U.S. department of health and human services, 2001) and "it includes education to advance understanding at all levels: how to prevent mental health problems, how to intervene early, and how to manage a mental disorder.” (p. 24, Ratzan, 2001 referred to U.S. department of health and human services, 2001).

A high level of mental health literacy leads to a medical understanding of mental disorders, to better mental health outcomes, to a process of reducing stigma quicker and to more appropriate forms of help (Fisher \& Goldney, 2003; Goldney, Fisher \& Wilson 2001; Jorm et al., 1997).

If we are interested in increasing public's mental health literacy, we should also bear in mind that it is connected to general literacy mainly because most of the health information is provided in form of reading materials. Consequently, a person lacking the literacy skills will be unable to access health information ( U.S. department of health and human services, 2001). This could be interesting information to be aware of, because Sweden is a country with many immigrants and ethnic minorities and these people often have poor literacy skills or they are literate in a different language. 
As mental health literacy is a quite recent term and a new scientific area, the number of existing studies is limited. Among countries that have studied mental health literacy, Italy, Malaysia and Australia, studies have been done in both public's ability to recognize mental disorders and the public's beliefs about treatment (Jorm et al., 1997; Magliano, Fiorillo, De Rosa, Malangone, Maj, 2004; Swami, Furnham, Kannan, Sinniah, 2008). When the results revealed lay public's poor mental health literacy, this led many of these countries to intervene through national awareness campaigns. The most representative one was the "beyond blue" campaign in Australia, which aimed at promoting health-based strategies and proved to be very effective (Hickie, 2004).

Sweden is still not among the countries that have employed an awareness campaign and this is maybe due to the fact that mental health literacy has not yet been adequately studied. There is only one study by Dahlberg, Waern and Runeson (2008) conducted in an adult Swedish population concluding that "mental health literacy was associated with a personal history of mental health care" (p.8). So, it is obvious that Sweden needs further research in order to recognize lay public's levels of mental health literacy and intervene if necessary.

\section{e. Adolescents' mental health and help-seeking behavior}

Adolescence is the time in life when the transition from childhood to adulthood happens and young people start to be independent from their parents. In this time of life, people are quite vulnerable because of the rapid physical and cognitive development. With regard to this master thesis, the reason that the selected population of this study is young people was because it is known that depression and psychotic disorders often have onset during adolescence or young adulthood (Manos, 1997). Moreover, the ages between 16 and 24 years have substantially higher rates of mental pathology than any other age (Australian bureau of statistics, 2006) and, despite of this, teenagers are less likely to seek help than older people (Bailey, 1999). However, it is highly probable that some of the adolescents will have contact with a peer with unmet mental health needs and this highlights why it is important to investigate young people's ability to recognize mental disorders like depression and schizophrenia and also to study their perceptions on treatment interventions.

WHO (2007) found that in some countries there is an increasing specialization in adolescent health with focus on their specific needs and problems and has defined adolescents' help seeking behavior as:

"the use of formal ....and informal supports which we define as health facilities, youth centers, formal social institutions or professional care providers, either in the public or private sector" and "family, kinship networks, friends, traditional healers and/or religious leaders....in the case of severe or serious mental health issues" (p. 7) .

There is evidence that help seeking behavior is learned behavior (WHO, 2007). This is an interesting finding, knowing that youth are influenced by adults and their parents' ways to cope with problems. But there are other factors too influencing adolescents' help seeking behavior, such as: "personal motivation, perception of need, 
self-agency, internalized gender norms, and perceptions of social supports as positive, among others”(p.9, WHO, 2007). Generally though, it has been found that in case of mental health needs, adolescents tend to turn for help to peers.

\section{f. Altruism}

Mental disorders might be hard to recognize. But even if they are recognized, how willing are people to care and help the person in need? Another purpose of this study was to examine adolescents' levels of altruism concerning help seeking behavior for a depressed or a schizophrenic peer.

"Altruism is generally understood to be behavior that benefits others at a personal cist to the behaving individual” (p. 135, Kerr, Smith \& Feldman, 2004). As Waenaken and Tomasello reported in their article 'The roots of human altruism' (2009) babies are naturally altruistic and "socialization and feedback from social interactions with others become important mediators of these initial altruistic tendencies” (p.455). Authors support that as people grow older they become more selective concerning their altruistic behaviors and their willingness to help others. One of the assumed motives behind altruistic behavior is empathy, meaning that people often identify with others' needs or pain and this makes them act altruistically in order to reduce the emotional arousal (Batson, 1991).

Altruistic behavior, compassion and social support make people feel elevated and good (Frederickson, 2003). Research has shown that kind emotions and helping behavior are associated with well-being, health and longevity. Generally, if helping behavior is not experienced as overwhelming, there are health benefits (Post, 2005). Post (2005) reported five benefits for those who behave altruistically: enhanced social integration, distraction from own problems, enhanced meaningfulness, increased perception of self-efficacy and improved mood. Moreover, it has been found that altruistic behaviors reduce depressive symptoms (Musick \& Wilson, 2003). In general, giving help has been more associated with better mental health than receiving help (Shwartz, Meisenhelder, Ma \& Reed, 2003) and adolescents who exhibited altruistic behavior grew up to be in better psychological and physical health than other peers (Wink \& Dillon, 2007).

\section{g. Stigma related to mental disorders}

There is evidence that a label of a mental disorder is stigmatizing. It has been found that both the general public and the mentally ill have stigmatizing attitudes concerning psychiatric illnesses (Hayward \& Bright, 1997). Stigma related to mental disorders has been defined by Hayward and Bright (1997) as "the negative effects of a label placed on any group, such as a racial or religious minority, or, in this case, those who have been diagnosed as mentally ill” (p. 346). Some of the common misconceptions about the mentally ill are that these people are dangerous, weak and socially incompetent (Wahl \& Harman, 1989). Canadian alliance on mental illness and mental health (2007) reported that research over the past decades shows an increase of fear related to mental disorders, especially related to schizophrenia. 
Hayward and Bright (1997) gave four possible causes for the origin of stigma. First of all, there is a strong association between mental illness and dangerousness. People are afraid of mentally ill because it is believed that they are more likely to be violent. Then, the mentally ill people are seen as responsible for their disabilities. Moreover, the misperception about mental pathologies that they are chronic conditions with a poor prognosis lead to even more negative attitudes. Finally, Hayward and Bright referred to the fact that the mentally ill don't follow the normal patterns of social interaction as another possible cause of stigma.

Generally people believe that mental health issues should be kept in private. Even teens, who talk with their friends about "anything”, think that discussions about these issues are uncomfortable and should be handled privately (Chandra \& Minkovitz, 2007).

\section{iii. Literature Overview}

One of the first studies on mental health literacy (Jorm et al., 1997) was conducted in Australia and revealed public's low ability to recognize depression (only 39\% of the study participants identified it) and schizophrenia (27\% of the participants correctly identified it). Another study in Switzerland, conducted by Lauber, Nordt, Falcato and Rössler (2003), used only depression vignettes and reported similar results. A study in South Africa (Hugo, Boshoff, Traut, Zungu-Dirwayi \& Stein, 2003) found that the majority of respondents didn't identify the mental disorders which were presented in vignettes, and they considered them to be stress related.

In Sweden there has been only one related study to my knowledge, entitled "Investigating the role of personal experience of mental health care"'(Dahlberg et al., 2008). This research compared "mental health literacy and attitudes among mentally healthy persons and in persons with symptoms of mental illness with and without treatment contact" (p.8). The study used depression vignettes and revealed that almost two thirds in all three groups (mentally ill and mentally healthy participants with or without treatment contact) failed to recognize depression.

A general consensus among the aforementioned studies is that psychosis is less likely to be identified than depression (Jorm et al., 1997; Keys, 1997; Wright, Harris \& Wiggers, 2005). Interestingly though, these studies also indicate that females (Burns \& Rapee, 2006; Cotton, Wright, Harris, Jorm \& McGorry, 2006; Dahlberg et al. , 2008; Jorm et al., 2006) and older people (Wright et al., 2005) are significantly better in making a correct diagnosis as compared to males and younger people, respectively.

However, it seems that it is not only the general population which is unable to identify mental illnesses. It is also health care workers themselves who can't correctly diagnose mental pathology, as the following studies indicate.

Paykel and Priest (1992) found in their study that only 50\% of patients who attended primary care physicians and depicted depression's symptoms were correctly diagnosed. Moreover, a study conducted in a psychiatric hospital in Singapore (Yeo, 2001), revealed nurses' inability to recognize depression and mania. Similar results have been found in South Africa, where almost all nurses (94\%) who participated in 
the study didn't identify mental disorders presented in case vignettes (Dirway, 2002). Finally, Bagley et al. (2000) showed that the majority of both nursing and care staff could not recognize depression.

Studies have also been performed investigating people's beliefs about treatment and appropriate help seeking behavior. According to McKinlay (1972), individual characteristics like personality traits and demographic characteristics, influence the pathways to care. A more recently study (Angermeyer, Matschinger \& Riedel-Helle, 1999) found that perception of the cause of mental disorders influenced respondents' decision about the best form of help.

Vitamins, minerals and special diets are highly rated from the public as treatments for depression (Jorm et al., 1997) while medication and psychiatric treatment is considered to be harmful (Fisher \& Goldney, 2003; Goldney, Fisher \& Wilson, 2001). Moreover, studies have showed that adolescents believe that informal sources of help, such as "talking to a friend" can be the most helpful "treatment" for a depressed or a schizophrenic person (Gifford-May, 2002, Farrer et al., 2008 and Wright et al., 2005), and they actually don't think that doctors can help (Burns' and Rapee's, 2006). But it is not only young people who prefer this kind of help in similar health issues. Parents also seem to trust more informal sources of help rather than mental health services (Jorm \& Wright, 2007).

Furthermore, in the study conducted in Sweden (Dahlberg et al., 2008) all groups (mentally ill and mentally healthy participants with or without treatment contact here is the three groups) suggested that between different available kinds of treatment, counseling or psychotherapy were regarded as the most appropriate interventions and most of the participants didn't believe that a psychiatrist could help. The study's authors interpreted participants' preference towards psychotherapy based on the fact that short-term psychotherapy (e.g. cognitive behavioral therapy; CBT) has become increasingly available in primary health care services in Sweden during recent years. Moreover, only 1\% proposed antidepressant treatment which is worrying if we take into consideration that antidepressant drugs are the most common medical treatment for major depression (Manos, 1997).

A study in Germany (Angermeyer et al., 1999) reported that locals believed that mental health professionals can help treating schizophrenia but not depression. This is an interesting finding considering the effect that it could have on people's attitude towards an eventual mental disorder. People for example won't turn to a psychologist if they feel depressed.

It is also worth mentioning that studies in developing countries, such as Nigeria, showed that a big percentage of respondents (34\%) considered traditional healing as the most appropriate form of help for mental illnesses (Kabir, Iliyasu, Abubakar ,Aliyu, 2004). Similar results were found in a study in Pakistan, where respondents preferred native faith healers for their mental health problems (Karim, Saeed, Rana, Mubbashar, 2004). Thus, it becomes clear that cultural attitudes are also highly related to lay public's beliefs of the appropriate treatment.

In contrast to the general population's beliefs about the best form of help for mental illnesses, there seem to be other beliefs among mental health professionals. A study conducted in Singapore among health professionals (Yeo, 2001) showed that nurses 
favored medically-based treatments and in a similar study in South Africa (Dirway, 2002) nurses seemed to prefer psychotherapeutic treatments over psychotropic drugs. Additionally, an Australian study (Caldwell \& Jorm, 2000) found that nurses and psychiatrists had the same beliefs about the interventions; that was antidepressants for depression and antipsychotic medication for schizophrenia. Finally, Australian pharmacists showed a positive attitude towards medication and psychological therapies (O’Reilly, Claire, Bell, Simon \&Timothy, 2010).

Most of the abovementioned studies have focused on help seeking behavior towards someone who is emotionally close to the participant. Lay public's willingness to help a mentally ill who is not a friend or a family member has not been explored yet. The latter, i.e. helping someone who is not part of one's close circle of family and friends, is highly related to altruistic oriented motives.

If and why people will choose to behave altruistically depends on many factors. Research shows that behind altruistic behavior there are different motives each time (Fehr \& Fischbacher, 2003). There are also some situations that evoke avoidance and block helping behavior. Piliavin, Dovidio, Gaertner and Clark (1981), found that one of those situations is when there is a "messy victim", for example someone who bleeds. Batson (1991) also supported that feelings of distress could cause a nonhelping behavior. Furthermore, it is more likely to ignore someone's need for help if escaping from the situation is easy (Batson, 1991). Studies on adolescents' altruism report that adolescents who behave altruistically are less likely to indulge in high risk behaviors (Eccles \& Barber, 1999). It is also interesting to mention that there is evidence that altruistic actions could reduce the risk for developing major depression (Taylor \& Turner, 2001).

It is well known that it is more likely to help someone who is emotionally close to you than someone else (Rachlin \& Jones, 2008). This is why people exhibit altruistic behavior to a greater extent towards family members (Eisenberg, 1983). These findings are also in accordance with results, showing that if someone will seek help for someone mentally ill, this will be a family member or a friend (Jorm, 2000). Moreover, Schwartz, Bell, Meisenhelder, Yunsheng and Reed (2003) found that older people and females are more likely to display altruistic behavior.

Earlier studies on psychiatric stigma revealed that lay public fears and dislikes mentally ill, and prefer to stay away from them (Hayward \& Bright, 1997). Research concluded that a number of factors affect levels of stigma. For example, Byrne (1997) found that students with knowledge of psychopathology were less likely to stigmatize. In agreement with the previous results, Chandra and Minkovitz (2007) found that students with a lower level of mental health literacy held more stigmatizing attitudes towards mentally ill. In the same study, teens reported that they would avoid a friend who had a mental disorder and perceived mentally ill as weak-willed.

Fear of stigma has been identified as an important barrier to help seeking behavior among adolescents (Chandra \& Miskovitz, 2007). As a consequence, people prefer not to disclose mental health problems in school or in the workplace because of fear of discrimination. There is also evidence that teenagers suffering from a mental disorder are exposed to higher levels of stigma than older people (Thara \& Srinivasan, 2000) and this may be due to the fact that younger people tend to have more negative 
attitudes towards mentally ill (Stuart \& Arboleda-Florez, 2001). Young people's stigmatizing attitudes have also been confirmed by another study which found that they tend to use strongly negative terms to describe mentally ill (Rose, Thornicroft, Pinfold \& Kassam, 2007). Some of these terms were "freak”, "psycho”, “nuts” and “crazy".

Finally, participants in a Canadian study were more descriptive about their conceptions of mental illness (Bourget \& Chenier, 2007). They reported that their views on mental illness included "images of out of control, violent or heavily medicated individuals and institutions" which evoked "fear, of danger or loss of identity” (p. 25).

\section{iv. Rationale of the Present Study}

\section{a. Purpose}

The initially set purpose of this study was to assess levels of mental health literacy among Swedish adolescents concerning depression and schizophrenia, and to examine levels of altruistic behavior towards a mentally ill. However, the content analysis led to the identification of one more related issue. This was the negative attitudes related to schizophrenia.

\section{b. Research Questions}

The primary research questions of the present study were the following:

- How do adolescents' perceive depression and schizophrenia?

- Which are these adolescents' beliefs about the types of help for depression and schizophrenia?

- How willing are they to seek help for a classmate who is mentally ill and who is not their friend?

- What kind of stigmatizing attitudes and beliefs are associated with schizophrenia among Swedish adolescents? 


\section{STUDY DESIGN AND METHODOLOGY}

\section{i. Design}

A cross-sectional qualitative study design was employed and data, collected from Swedish adolescents using vignettes, were analyzed using a content analysis method.

\section{ii. Participants and data collection process}

The study group consisted of 426 adolescents studying at two high schools in Stockholm, Sweden. The mean age was 16,1 years old (age range 15-19) and most participants attended either a natural science or a social science program.

The schools were opportunistically chosen as follows: High schools located within Stockholm's municipality were randomly selected from an on-line database (www.hittaskola.se) and e-mail requests for participation were sent to the school directors. As a result, two schools (Internationella Engelska Gymnasiet Södermalm; IEGS, and international baccalaureate school south; IB school south) accepted to participate and the school directors were handed the vignettes together with information about the study (see appendix 1).

During mentor hours, and in some cases during lesson hours, students were handed out the vignettes from their mentors or teachers, respectively, and were invited to participate. It was highlighted that participation was voluntary and anonymous. The only personal information included on the vignettes was gender, age and type of educational program. Following the vignette completion, students were handed out answers to the presented scenarios (see appendix 3).

The non-participation rate could not be accurately estimated as students might have been absent during the time when the vignettes were administered. However, if all students had been present, the non-participation rate would have been $23 \%$.

\section{iii. The vignette}

An already established vignette (see appendix 2), originally developed by Jorm et al. (1997), was adapted and utilized to fit this study's aims. In the original vignette, Jorm et al. (1997) created two scenarios in order to assess people's ability to recognize depression (scenario 1) and schizophrenia (scenario 2), and their knowledge about the appropriate professional help. These two scenarios (with minor alterations; see below) were presented and were followed by three open-ended questions:

a. Is everything fine with John? If not what would you say is wrong with him?

If you thought that something is wrong with John, continue and answer the following questions:

b. -Imagine John was a friend of yours that you cared about. You want to help him. What would you do? 
c. -Imagine John was a classmate that you did not know so well. What would you do?

The two first questions ( $\mathrm{a}$ and $\mathrm{b}$ ) were adopted directly from Jorm' et al's vignette. Question "a” was designed to check the mental health literacy of the respondent, while question "b" was intended to identify respondents' perceptions about best sources of help if John was a close friend to the respondent. The third question was a newly added one (not adopted from Jorm' et al's original vignette) and aimed at assessing levels of altruism; in particular how the respondent would have reacted if John wasn't a close friend but just an acquaintance.

Both scenarios depicted an imaginary person (named John) who satisfied the symptomatology of either depression or schizophrenia according to the Diagnostic and Statistical Manual of Mental Disorders, 4th Edition (DSM-IV) as well as International Statistical Classification of Diseases and Related Health Problems, 10th Revision (ICD-10).

Both a male and a female character were used in Jorm' et al's (1997) study but only a male character (John) was chosen for this study, as the original study showed no effect of gender on vignette response. Moreover, the original version of the vignette presented a 30 year old person with depression and a 24 year old with schizophrenia. As the present study examined a younger audience, it was also adjusted accordingly and the person described (John) was said to be17 years old. Additional adjustments/changes that were made to the vignette to fit the audience were as follows:

Original depression vignette:

"He can't keep his mind on his work and puts off making decisions. Even day-to-day tasks seem too much for him. This has come to the attention of his boss, who is concerned about John's lowered productivity”

Replacement of the above in the present study by:

"He has difficulties in concentrating in school and his results are less good".

Original schizophrenia vignette:

"He has had a few temporary jobs since finishing school but is now unemployed"

Replacement of the above in the present study by:

"He has stopped going to school".

The vignettes were in English as the two schools that agreed to participate were English speaking. However, translated versions in Swedish had also been prepared in case Swedish speaking schools would have agreed to participate.

\section{iv. Data analysis}

All answers to the gathered vignettes were transcribed verbatim using word processing software (Microsoft Word for Windows). The data were analyzed using a content analysis according to Burnard (1991).

In particular, according to Burnard there are fourteen stages to follow during the procedure: during the first stage, notes and memos were kept for each vignette 
depicting everything considered to be important, in addition to ideas on how to categorize the data. Then, all transcribed vignettes were read and reread to get immersed in the data and to find general categories. In stage three of the analysis, all superfluous text which seemed to be unnecessary for the content analysis was omitted. Data was then reread numerous times in order to let categories be "freely" generated. Subsequently, all identified categories were indexed into more meaningful and broader categories. During the fifth stage of the analysis, categories were refined and subcategories were generated leading to a final list. In the next stage, all categories found were discussed with my supervisors in order to reduce bias and increase internal validity. Adjustments, if necessary, were at that point made and all data within categories was reread. On stage eight, categories and subcategories were coded. Then (stage nine) every coded section of data was cut out and (stage ten) pasted onto sheets with the headings and sub-headings. Categories were checked again (stage eleven) and results were read (stage twelve) and the original vignette transcripts were consulted if something felt incomplete or unclear. In stage thirteen, the writing process started and representative citations were selected. In the final stage, all findings were presented and then compared to the previous literature.

\section{v. Ethical and copyright considerations}

This study was in accordance with the basic ethical principles and guidelines for scientific research in the humanistic-social sciences given by the Swedish council for research. Participation was voluntary and anonymous, and according to the study's supervisors no ethical permissions were needed for performing this study. The vignettes were adjusted and reproduced after receiving copyright permissions by the Australasian Medical Publishing Company (AMCo). AMCo is owner of copyright for all material published in the original publication: "Jorm AF et.al. "Mental health literacy": a survey of the public's ability to recognize mental disorders and their beliefs about the effectiveness of treatment. MJA 1997; 166: 182-186. 


\section{RESULTS}

Following the qualitative data analysis, respondents' answers were organized within the following sections: A. Mental health literacy about depression, B. Forms of helping a friend with depression, C. Mental health literacy about schizophrenia, D. Forms of helping a friend with schizophrenia, E. forms of helping a peer with depression or schizophrenia, and F. Stigma and attitudes towards schizophrenic symptoms. It should be pointed out that every section was analyzed independently, meaning that the results were not based only on individuals who recognized depression and schizophrenia. All categories and subcategories that emerged from the analysis are presented below, in addition to representative citations. A brief presentation of the categories and subcategories that emerged from the content analysis is found in tables 2 to 6 (Appendix 4).

\section{Section A: Mental health literacy about depression}

After reading the vignette presenting an imaginary person (John) with depression, participants were asked the following: "Is everything fine with John? If not, what would you say is wrong with him?”

During the content analysis concerning mental health literacy about depression, three categories emerged: A.1) recognition, A.2) misrecognition and A.3) no problem recognized. There were also five subcategories: "stress", "personal problems", "physical problems", "lack of interests” and "unidentified problems”. A more detailed presentation of the results will now follow.

\section{A.1) Recognition}

Many respondents (136 out of 436) were capable of recognizing that John was experiencing a depression:

"He is depressed and (doesn't) feel happy. That affects his physical health too." "I would say he is in depression. Depression has the consequences that John has."

Among respondents who correctly recognised the symptoms of depression, there were those who were not sure about their view of the problem. Here are two citations indicating respondents' uncertainty:

"He is probably depressed"

"Everybody has some issues to go through in this age. Maybe it is depression maybe it is not."

Moreover, there were also those who did not believe that the fictitious character's symptoms indicated a problem in the present moment, but they perceived them as signs of future depression if nothing changed soon.

"Everything is fine physically with john but maybe he has had a "dip" mentally. There does not need to be a reason for this except 
that he is a teenager with mood swings. This may have caused... a

bad circle which may lead to a depression."

Furthermore, most of those who recognized depression perceived it as a temporary phase and something normal for someone at this age:

"... he is not ok. In this age you are in a position when you feel

depressed but that's normal, he will get over it."'

"... he is probably just having a teenage depression. I would say that it most

likely is a passing phase."

In addition, there were also respondents who, even if they recognized the symptomatology, didn’t seem to regard depression as a clinical condition requiring attention:

"Yes, everything is fine, except his depression"

"I think that he is just depressed"

Finally, it was interesting to see that there were respondents who made an estimate of the problem's severity:

“... he seems mildly depressed."

"I would say he is suffering from depression, however not a very strong one"

"It seems that he has a minor or a beginning of depression."

\section{A.2) Misrecognition}

Many respondents realized that something was wrong with John but misevaluated the situation presented in the depression vignette and didn't cite depression. Most common interpretations were stress, personal problems, physical problems and lack of interests.

\section{Stress}

There were respondents who believed that the fictitious character presented in the scenario was just too nervous and couldn't handle pressure effectively. Moreover, one other reported cause of stress was that John was going through puberty. They believed that he was stressed because students believed that being an adolescent means experiencing a complicated and demanding phase in his/her life whereas he/she feels responsible for the future and start acting as an adult. This kind of stressful life situations could function as source of pressure and lead someone to similar behaviors:

"I think he is stressed because of too much to do... it is an age where this is normal since this is the time you pretty much decide what you want to do with your life. This could damage you mentally."

"It seems like he is very stressed. I think most of it comes from school. He also seems very sad all the time maybe... that's because of his age. A lot is going on around him and he might not really know how to handle these things."

"... he is stressed out I would guess... these years at school are very intensive and there are also many changes in relationships between both friends and yourself." 


\section{Personal problems}

Respondents belonging to this category thought that a personal problem had affected John and that his behavior was a consequence of a negative incident. Among the most common problems to which participants referred to, were problems in love relationships, family concerns and social problems. Moreover, respondents highlighted the fact that adolescence is a phase of increased emotional sensitivity, as they described how hard it is being a young person and how easily they are affected during this age by personal relationships, e.g. a "broken heart", a fight with a friend, and disagreements with parents:

"it can be his social life that is affecting him, i.e. he (doesn't) have many friends or (is) miserably in love."

"... maybe he is having (a) family problem or he is taking too much tension about something or he (is) feeling lonely."

Additionally, some participants believed that John's behavior was a result of being bullied at school:

"I don't think that he realizes himself but something must have snapped. One reason could be that be finally got bothered with what a (bully) said though he usually got bad comments."

\section{Physical problems}

There were respondents who interpreted the depressive behavior as being a cause of a non-mental health problem such as an infection or a metabolic disease:

"... he could have gotten some kind of virus or bacteria"

"He might be (carrying) a disease of some sort..."

"...he maybe has AIDS."

"The symptoms points towards diabetes."

There were also respondents who believed that John was nutritionally deprived; something that could eventually lead to other types of mental disorders:

"Maybe he has too little iron in his immune system or he can have a loss of something else (vitamin) that's disturbing his immune system."

"...he seems to have some sort of nutrition problem, maybe a lack of iron in his blood. This may lead to anorexia."

\section{Lack of interests}

There were respondents who interpreted John's behavior as a result of no interests in life:

"I would say that he is bored \& tired that nothing is happening in his life and somehow lost meaning in life."

"...or he maybe have lack of hobbies. Music, sports and other social activities cheer people up \& is very important especially for teenagers."

Additionally, some respondents perceived depression as a result of bad habits which reinforce John's negative life patterns: 
"He is in a vicious cycle ... not eating or sleeping leads to... being constantly tired and miserable. He is miserable so he won't eat and won't be able to fall asleep."'

"he is stuck in a bad circle. Maybe he didn't sleep one night and then he can't eat and it just continues."

Unidentified problem

Finally, in this category there were respondents who were capable of understanding that something was wrong with John but they were unable to identify the exact nature of the problem:

"Something is wrong with him. He needs to go to the doctor because I don't know exactly what's wrong with him."

"It is hard to say exactly what it is but something is wrong that's for sure."

"Everything is not fine with him but I really don't know what has happened with him. No idea!!”

\section{A.3) No problem recognized}

It was interesting to see that a portion of respondents (11 out of 426) didn't refer to any kind of problem concerning John's behavior. Instead, they claimed that nothing serious was wrong with him:

"That's normal he will get over it."

"Everything is fine with him all he needs is a bit of company and some beer and everything will be alright."

\section{Section B: Forms of helping a friend with depression}

The second part of the depression vignette stated the following: "If you thought that something is wrong with John, continue and answer the following questions: Imagine John was a friend of yours that you cared about. You want to help him. What would you do?”

Three main categories emerged from the qualitative data concerning the best forms of help for a friend suffering from depression: B.1) informal sources of help, B.2) formal sources of help, and B.3) no help. Nearly all the respondents, who were categorized in sections B.1 or B.2, identified more than one source of help. There were also respondents who suggested a combination of both formal and informal sources of help for dealing with depression. A detailed presentation of the results will now follow.

\section{B.1) Informal sources of help}

"Informal sources of help" refer to any form of help provided by any means or source other than healthcare workers. The majority of respondents chose an informal form of support, or a combination of many informal types of help, for a depressed friend (378 out of 426). Types of informal sources of help were classified into seven subcategories: "personal communication", "relaxation and entertainment", "nutrients and sleep”, “adult help”, "being supportive” and "sexual intercourse”. 


\section{Personal communication}

Respondents referred to "talking" as an appropriate way of helping a depressed friend and considered conversation to be the best they could do for helping someone to cope with his unpleasant feelings and behaviors. Respondents also stated that by listening to the other person, rather than seeking help from an external source, would be more helpful. They thought that by verbalizing their friends' thinking would help them to explore the problem's nature and properly advise him:

"I would speak to him and together with him try to find out what the source of this behavior is. Talking almost always makes a difference."

"Encourage him and show him that you're by his side through it all. And be sure to tell him that "after rain comes sunshine" to cheer him up and give him hope."

Relaxation and Entertainment

Respondents also believed that a good way of helping John was to suggest some time for relaxation and various relaxing techniques were suggested:

\footnotetext{
"Try to persuade him to seek help or meditate or something spiritual"

"I would help him with some yoga moves I know so that he can relax"

"I would ask him to not stress so much and maybe sign up for some stress management groups."
}

Moreover, hobbies, activities and entertainment were also mentioned as ways of making someone feel better and maintain his/her health:

"Music, sports and other social activities cheer people up \& (this) is very important especially for teenagers. I would ask (John) to join me (in) my activities so he gets

busy and stops "thinking about unnecessary things" which usually lead to depression."

"I would try and take him out and have some fun with him possibly go to a party or just hang out together."

Nutrients and sleep

There were respondents who thought that by taking care of some basic nutritional and physical needs would help John to overcome his problem. In particular, a right diet was considered important as a means of reversing John's symptoms. Thus, self-help interventions, such as eating better and sleeping more, were suggested:

"Try to give him advice that (would) help him with his sleeping problem, e.g. move the electronic apparatus out of his bedroom, drink warm milk before sleeping etc." "Say to him to strengthen his inner immunity against bacteria by eating healthy food such as proteins, vitamins or onion."

Adult Help

Some respondents preferred turning to an adult for help or would try and convince John turning to one. Teachers and family members were among the adult help that was suggested:

"I would contact a grownup. Someone at school or a family member." "I would ask someone older for their opinion." 


\section{Being supportive}

Being a good friend and having a supportive role were stated as ways of helping their friend in need. Respondents would, for example, offer positive reinforcement and be physically present:

“...encourage him and show him that you're by his side... And be sure to tell him that 'after rain comes sunshine' to cheer him up and give him hope"

"Handle (him) with care and understanding"

Additionally they would be willing to express their support through small and everyday gestures concerning more practical issues:

"Help him get his life straight: clean his room, do missed homework and (if) possible fit bad relationships."

"I would be (there) for him a lot more often and support him in all ways. Love is great free medicine for any problems/sickness!"

Sexual intercourse

There were also those who believed that being sexually active would help:

"Some sexual healing would help."

"Tell him to see a doctor or a bordello."

\section{B.2) Formal sources of help}

Even if most respondents described an informal source of help as described in section B.1, there were also those who suggested a more formal source of help. Within this study's context, formal sources of help refer to professionals/employees whose duty includes helping people.

Respondents suggested as formal sources of help: "general practitioners", "school counselors and nurses”, "social workers and therapists”, "psychologists”, "psychiatrists and medication".

\section{General Practitioners}

Under this subcategory respondents suggested visiting a “doctor”. By stating “a doctor" in Sweden people usually refer to a general practitioner or a "family doctor" rather than a medical specialist:

“...I would convince him to speak with a doctor to help him in the process of reforming back to his old self."

"I would tell that person to maybe see a doctor so the doctor could tell my friend if something is wrong."

School counselors and nurses

A school counselor or nurse was also considered to be helpful in order to find out what the exact problem is. Respondents mentioned that they would either go to the school counselor themselves in order to get some information about the situation, or that they would suggest their friend to visit one:

"Maybe go to the (school) counselor and ask him what I can do to help." 
"I would advise him to talk to a professional, for example the school counselor." "I would personally see... that he visited the school nurse."

Social workers and therapists

Social workers and therapists were also states as suitable sources of formal help:

"I'd contact some authority or recommend him to go see a social worker or similar" "...try to talk to him to go to a therapist that might be able to help"

"Perhaps suggest therapy sessions, so he can perhaps work on how to handle it."

Psychologists

Visiting a psychologist was also mentioned among the formal sources of help:

"I would also try to convince him to see a psychologist to find the source of this depression."

"I would get him to try and see a psychologist so they could judge what is wrong with him.”

Psychiatrists and medications

Respondents also brought up medical specialists and different medical drugs as helpful means:

"...tell him to go and see a shrink and ask why he feels like this."

"Help him to get in touch with a psychiatrist (personal experience, it is needed)."

"I would tell him to take a (painkiller)."

"I would ask him to consider going to a doctor and get some drugs, maybe antidepressant drugs in this case."

"...get sleeping pills."

“...needs medication that releases 'fake happy hormone'.”

\section{B.3) No help}

There were also respondents who mentioned no source of help. They reported that they wouldn't intervene at all either because they felt unable to help or because they thought that their friend has to find a way out all alone:

“There is not much I can do since I wouldn't recommend (Child and Adolescent Psychiatry Service) to anyone." "(there is) nothing you can do about unreasonable misery but wait." "...he should try to change himself."

\section{Section C. Mental health literacy about schizophrenia}

In Case II of the vignette, the imaginary person (John) was presented with symptoms of schizophrenia. Following the case presentation, the participants were asked: "Is everything fine with John? If not, what would you say is wrong with him?”

Below follow the results of the content analysis for recognizing schizophrenia. The categories that emerged were the same as for recognizing depression and are divided in three parts: C.1) recognition, C.2) misrecognition and C.3) no problem recognized. 


\section{C.1) Recognition}

Some respondents (116 out of 426) were able to correctly identify schizophrenia, or state a psychotic condition, in the second vignette. Respondents who recognized psychotic features usually referred to both schizophrenia and paranoia:

"I would say that John is suffering from constant paranoia and, to an extent, (from) schizophrenia."

"he seems to be schizophrenic or suffering from some sort of psychosis."

Some respondents under this category also made judgments on the severity of the mental disorder:

$$
\begin{gathered}
\text { "(John is) perhaps schizophrenic at an early stage" } \\
\text { "He suffers from acute paranoia" }
\end{gathered}
$$

In some cases respondents were not really sure but guessed correctly on the answer:

"I don't really know what is wrong with him. Schizophrenic??”

There were also those who answered correctly with a bigger certainty:

"He has a type of psychological disease called schizophrenia."

"He is probably schizophrenic... it is a mental disease where you hear voices."

\section{C.2) Misrecognition}

The majority of the teenagers could not correctly identify schizophrenia and the explanations given for John's behavior fall into six subcategories: "social isolation", "social rejection”, “insecurity”, other disorders”, “drugs” and “unidentified problem”.

\section{Social isolation}

Many respondents thought that John had been socially isolated and mentioned e.g. loneliness as an attributed reason for his unusual behavior:

"He feels alone... he feels worse than others, maybe is shy and unsocial." "He seems very alone or misunderstood so it seems he is made up his own reality" "... he is a social outcast."

There were also those who believed that John created an imaginary friend to cope with this social rejection:

"...he isn't treated well at school and most probably has no friends. That is why he created an imaginary friend and spends all of his time alone in his room. Because in his room there is nobody to judge him."

"Everybody have imaginary friends and it (is) perfectly normal to hear children interact with them ..."

\section{Social rejection}

Others thought that John exhibits this kind of behavior because he has been bullied at school. Consequently this has affected his sense of security and he is reacting this way. 
"he is being bullied and made up a story about spying neighbors because he doesn't want to tell the truth.”

"Or he is being bullied at school and doesn't want to go outside because they might come after him or something."

Insecurity

Other respondents answered that John behaves this way because he is afraid of something for some reason:

"I think he is afraid of something... school, parents, etc."

"Something happening that really has scared him out \& (he) doesn't have the heart to go out. He might have seen something out on the street, which he shouldn't have done, and this make him scared of almost everything."

Other disorders

Several respondents identified schizophrenia as a disorder, like depression, multiple personality disorder, or Asperger syndrome. In some instances, psychotic symptoms, like persecutory delusions, were identified as a cause of illness rather than a symptom:

"He is not ok... he is highly depressed about something."

"maybe he's got multiple personalities or a psychiatric disease."

"no he might be suffering from amnesia."

"I would say that he is autistic."

"he has Asperger (syndrome)"

"He has (persecutory delusions) believing everybody spies on him (and) wants him ill."

There were also those respondents who understood that John was having a disorder but couldn’t put a name to his condition:

"I would say that he was mentally sick or that it is something psychological wrong with him."

"He has some kind of sickness which makes him think that everyone is spying on him..."

"...or maybe he has some hereditary disease."

\section{Drugs}

Despite that in the description of case II it was stated that "John is not taking drugs because he never sees anyone or goes anywhere", there were still some respondents who weren't convinced and suspected substance abuse as the cause of John's strange behavior:

"it is something that is distracting him. Like an addiction or something else."

"I think that john is taking drugs even if his parents think he is not."

\section{Unidentified problem}

Finally, some of the respondents could understand that something was wrong with John but made no further assumptions on the possible causes: 
"well something is definitely wrong but I don't know what."

"of course something is wrong but it is not obvious what it is..."

\section{C.3) No problem recognized.}

Despite the obvious psychotic symptoms that the fictitious character exhibited, there were still some respondents who found this situation not of concern:

"I think he needs some time alone... with time he will be fine."

"Of course he is fine... he is just a weirdo."

"he might just wanna think about some stuffs. Does not mean that it's something wrong with him.”

\section{Section D: Forms of Helping a Friend with Schizophrenia}

The second part of the schizophrenia vignette -just like the depression vignette- stated the following: "If you thought that something is wrong with John, continue and answer the following questions: Imagine John was a friend of yours that you cared about. You want to help him. What would you do?” As in section B, three main categories emerged again from the qualitative data concerning the best forms of help for a friend suffering from schizophrenia: D.1) informal sources of help, D.2) formal sources of help, and D.3) no help.

\section{D.1) Informal sources of help}

As with depression, respondents referred to informal sources of help meaning any form of help provided by sources other than professionals. Three subcategories emerged: “communication”, "adult help” and "social life and entertainment”.

\section{Personal communication}

Nearly all respondents believed that being more open towards a schizophrenic person and letting him know that they were there for him would be helpful. In this case, giving some sort of verbal and communicative support was believed to be enough for helping someone:

"I would try to talk to him and meet him and try to get him back to normal...prove to him that there is nothing to fear."

"I'd talk to him, ask him how he was feeling... just try to get him to speak out and the true problem may reveal itself."

Moreover, in the schizophrenia vignette, most respondents seemed to be quite confused with the character's situation and not being able to understand what exactly is going on. This is why they preferred to write that they wouldn't react immediately but that they would spend more time on investigating the situation. They would look more closely to the problem in order to understand and document the events:

"I would get him on the phone or talk to him face to face, whether he wants to or not. Just try to talk (to) him and try to understand what's going through his head. I will then try to help him."

"I would go home to him and try to talk to him. See if anything/what's wrong with him... talk to him, I need to know what the problem (is) first." 
Moreover, there were respondents who were uncertain whether John's neighbor was really spying on him or not. This is why they focused only on this information given in the vignette and they stated that it would be something that they would investigate in depth. They would get John's neighbor involved or even the police. Or they would try to persuade John that no one is really spying on him, if they finally understood that this was not true:

"I would try to talk to him and make him go outside. Or else I would bring his neighbors to show him that they are perfectly normal."

"I would speak to him and try to get him to break the habit and see that his neighbor isn't spying on him. If the neighbor (was) really spying I would call the police."

"I would try to ensure him that his neighbor is not spying on him and try to convince him that... spying is part of the life."

"...talk to him, maybe stay with him for a couple of days to see if he was (telling) the truth or if he just imagined things."

Adult Help

Adults, like parents and teachers, were highly regarded as a source of help. It seems that the respondents, feeling unable to help as they are inexperienced with this kind of situation, would prefer to turn to someone older and more experienced in life:

"I would first try and talk to him but I don't think it would work in this case so I would probably talk to a teacher or my parents"

"I would make him get help preferably with the help from his parents. His condition could be dangerous."

Social Life and Entertainment

As schizophrenia's symptoms were perceived as signs of loneliness, it is not surprising that several respondents believed that socializing more would be effective in John's case:

"I will encourage...him to meet my friends... have some fun, drink or play something nice that could entertain him."

"I would try to involve him in outdoor activities or do things that would trigger his social life back into place as I believe that (this) is the reason for his bizarre actions."

Additionally, there were respondents who believed that John had to be entertained somehow; even if that meant forcing him to do so:

"I would take him out (even...by force) so he could chill down and he could make some friends."

"I would encourage him to go out, to movies or lunch etc... or maybe just do something fun at his house."

\section{D.2) Formal sources of help}

Several types of formal sources of help for the schizophrenia case were identified. Formal sources of help included the following: "general practitioners", "psychologists”, "therapists and counselors”, "professional help”, "mental hospitals 
and medication”. The various formal types of help reported by the respondents are examined below.

\section{General Practitioners}

It was more likely that general practitioners, commonly referred to as 'doctors', were chosen as the best form of formal source of help. Not only did respondents say that it would be helpful if John would be diagnosed by a professional, but doctors were also perceived as a reliable source of getting more information about his situation:

"I would try to make him meet the doctor and get diagnosed."

"I would talk to a doctor about this problem \& try to make him see one."

Psychologists

Several respondents wrote that they considered psychological help as a good means of formal help:

"I would try to listen to what he has to say and speak to psychologist. I would tell him to go see a person that understands and can help him."

Psychiatrists

Some of the respondents reported that a schizophrenic could best be helped from psychiatric services:

"I would try to talk to someone, a psychiatrist for example. Because this is so serious that simply a friend who's a good listener won't help."

"I would not tend to help him by myself. This case is too big for me. I would send him to a psychiatrist."

\section{Therapists and counselors}

Moreover, respondents would advise the schizophrenic to consult a therapist or a counselor:

"I would tell that person to see a therapist so he/she could get rid of the problems." "... try to talk him into counseling. This feels too big for me to handle on my own."

"I would advise the parents to contact a counselor (and) bring (him) into his home and talk to him."

Other professional help

There were also respondents who wrote about expertise help in general without being specific on what kind of professional this would be:

"tell his parents to seek professional help for him."

"I'd call people ... with expertise (on) the minds of teenagers."

Hospital

Some of the respondents considered the symptoms presented as signs of a serious problem needing immediate care. So, they recommended the admission to a hospital or a psychiatric clinic to get the treatment needed in this case. Even involuntary admission was suggested: 
“Take him to a mental hospital."

"Suggest to his parents to take him to the good specialist and to put him in specialized clinic."

"I would probably try to get him to a hospital (as) soon as possible."

\section{Medication}

For some students, medication was considered to be the appropriate treatment for these symptoms:

"I would take him to a real doctor so that he could be diagnosed and be given real medicine so he could become better."

\section{D.3) No help}

There were also respondents who reported that they would either not seek any kind of help if John was their friend or that that they didn't know how to help. And this was not because they felt that John didn't need any kind of intervention but mostly because they would be scared and wouldn't want to get involved in any way with a "dangerous" and "weird" person:

"I would leave him alone because these people can be very easily aggressive." "I wouldn't care about someone who's acting weird like him from the beginning..."

"Nothing... let him be alone as he wants... I don't want to have psycho friends."

Some reported that even if they understood that there was something wrong, they wouldn't intervene in any way because they considered that there is no help for such situations:

"there is not much to do."

Finally, as mentioned above, several respondents reported that they didn't know how to handle this situation:

“To be honest I don't know”

"no idea"

\section{E. Forms of helping a peer with depression or schizophrenia}

Both the depression and the schizophrenia vignettes were followed by a third question that read "Imagine John was a classmate that you did not know so well. What would you do?” This question was used as a means of exploring adolescents' altruistic attitudes towards a person in need who isn't their friend, i.e. a peer. Through the content analysis of this question, participants' altruistic behavior was studied. Three categories arose from this analysis: E.1) Direct altruistic behavior, E.2) Indirect altruistic behavior and E.3) Non-altruistic behavior.

\section{E.1) Direct altruistic behavior}


Many students did not differentiate their answer in this question from the answer in the previous question (i.e. if John was a close friend) and said that they would help John even if they did not know him that much.

Personal communication

Adolescents believed that through conversation they would be able to help him.

"I would probably do the same thing as (if) he was my friend, I would talk to him." "(I would) try to talk some sense into him."

\section{Professional help}

There were also those, who considered that a professional would be more capable of helping their peer and this is why they would advise him to visit one.

"advice him to go talk to someone, psychologist or guidance counselors." "Ask him to go to professionals."

\section{E.2) Indirect altruistic behavior}

Others showed willingness to help a peer even if they didn't know him so well, but they would not do it themselves.

\section{Friends}

They would prefer to ask for help from a friend of his, because he/she would know him better and would be more able to help him out.

"I would perhaps tell his friends that they should help him out more and be concerned for him."

"... I would ask a good friend of his if they have noticed that he is behaving strange. If yes then I would leave it to them. I wouldn't want to get involved. He probably would like to deal with it together with people he knows."

Family

Respondents reported that they would turn to their classmate's family in order to inform them about the situation and then leave them to deal with it.

"I would just go straight to his family and tell them."

"I don't think I would help him directly however I would do it indirectly. Like through his parents, siblings.."

\section{E.3) Non-Altruistic Behavior}

Finally, there were respondents who wrote that they would not proceed with any kind of help and they referred to two reasons for their answer.

Indifference

Some of them explained that they would simply not care for someone who is not their friend either because their lack of sensitivity or because they simply don't feel that it is their responsibility to do something about it: 
“...ignore it completely. I have to be honest.”

"...not give a crap."

"...not care... feel sorry but not do anything."

"I wouldn't do much... because I don't know him. I would feel as if it wasn't any of my business."

\section{Discreetness}

Others stated they would not take the initiative to help someone that they don't know because it concerns a health issue and they should be discreet.

"I would not do very much as I don't know him. It is hard to give advice to someone who you don't know well because you feel you are intruding on their private life." "I don't think that someone I don't know so well would be happy if I started digging in their personal life. He probably has closer friends who would be better suited."

\section{F. Stigma and Attitudes towards Schizophrenic Symptoms}

During the content analysis of the schizophrenia vignette, an additional main category arose; "forms of stigma”. Stigma was manifested through the use of derogatory words for the mentally ill, for example "he is a psycho", "he is maybe going nuts", "he is just a weirdo", "he has gone mad”, "he is a psychopath or just creepy”.

\section{F.1) Forms of Stigma}

The reported negative terms indicating forms of stigma fell into two subcategories: "fearfulness" and "rejection".

Fearfulness

Some respondents described a person with schizophrenic symptoms as dangerous and with unpredictable behavior. In particular, they said that they would be scared of him. The following citations by some respondents illustrate the myth of the dangerous schizophrenic person:

"I would get scared, really scared!!!"

"The man is paranoid... send him to a proper facility or he's going to kill somebody." "would tell him that he is getting scary and that he needs to seek help immediately.",

\section{Rejection}

Respondents' prejudice towards a person with schizophrenic symptoms was shown by the repeated characterization of such a person as being weird and crazy. Therefore respondents admitted that they would hold a discriminatory behavior, refuse to help this person, and use ways of rejecting him e.g. by bullying:

"...bully him for being weird."

“...I would probably think he is crazy and not try getting involved." "I wouldn't talk to him at all, just think that he is weird." "just stay away from him."

"Nothing, (I would) let him be alone... I don't want to have psycho friends." 


\section{DISCUSSION}

\section{Choice of research method}

Research methods are commonly classified in two categories, qualitative and quantitative methods. My decision for choosing research method was based on my study's aim and my research questions. As I have already mentioned, my aim was to understand how Swedish young people think and feel about depression and schizophrenia and their beliefs about the appropriate treatment. This is considered to be a quite complex and sensitive social phenomenon which is difficult to investigate appropriately by a quantitative methodology and pre-coded categories (Langemar, 2008). Pre-coded categories were excluded because I wanted to rely on my respondents' own representations. Moreover, I used a qualitative method because I was interested in questioning, as I did not know what to expect, and not in measuring. I sought to understand respondents' worldviews in terms of mental illness and their own beliefs about the best form of help. Besides that, conducting a data driven study enabled me to be more flexible when collecting the data, by using vignettes with open-ended questions (Langemar, 2008). A necessary tool for achieving my goal was to have an exploratory form of data which would allow me to explore the studied topic in the original language of research participants (Patton, 2002). This is why data consisted of direct quotations from people about their experiences and their feelings, meaning in form of texts, which is a non numerical-form as qualitative research demand.

But, choosing this type of study had also some disadvantages. First of all, analyzing the data was quite difficult and time-consuming because the qualitative data were long and variable in content and I had to discover similarities within these varied data. Furthermore, this method's results are subjective because the qualitative researcher is the one who decides what is important or not for the content analysis.

\section{Choice of Method When Collecting the Data}

My study was built on a previous study conducted by Jorm et al. (1997) so I used an identical method, meaning vignettes.

Vignettes have long been used to study attitudes, perceptions, beliefs and norms within social science (Finch, 1987). It is a choice of tool to use within qualitative, quantitative or even mixed methods. Hughes (1998) defined and described the use of vignettes:

'Participants are typically asked to respond to these stories with what they would do in a particular situation or how they think a third person would respond. Vignettes often represent a selected 'snapshot' containing limited information on which participants are asked to comment. Consequently, responses are often characterized by the 'it depends' answer, which provides the situated context for participants to offer and define central influencing factors. Work situated in qualitative paradigms have been central sites for capturing and exploring these complex situational positions ascribed by different actors" (p.381). 
A foremost benefit of vignettes is that vignettes permitted me to explore adolescents' evaluations on the scenarios presented in their own terms. It was an effective way making respondents engage with the story and offer their own evaluations and perceptions for the situations presented. Vignettes facilitated adolescents communicating their thoughts as it is not a method requiring eye contact (such as interviews for example) and therefore created a non threatening condition. Avoiding the personal contact with respondents during the data collection procedure was also positive because the researcher did not affect responses in any way.

Moreover, this study is about two mental disorders (depression and schizophrenia), a quite sensitive issue and this method was useful in engaging respondents to be honest and open without feeling exposed; it is neither uncomfortable nor threatening commenting anonymously on a scenario.

It is also the correct method to use when you don't know if the respondents have a personal experience on the studied issue or not, so I was able to "compensate for a lack of direct experience” (Barter \& Renold , 2000). Students were also able to choose themselves if they would introduce their personal experiences to their answers or not in order to make their abstract responses more concrete, as there were no questions about personal issues.

Furthermore, vignettes minimized possible ethical issues, in contrast to interview based studies for example (Wilks, 2004). They were also ideal for gathering data from a big sample and were not time consuming and this gave me the opportunity to collect many questionnaires in a short time (Jergeby, 1999).

But of course using this method had also some limitations. First of all, the disadvantage of using this method is that the scenarios presented are fictitious and I can't really know if respondents' answers reflect a similar attitude in real life situations. But, Hughes et al. (1998) argued that responses to vignettes do not differ to a large extent from people's reactions in a real life situation. Moreover, researchers who created and used these scenarios (Jorm et al., 1997) tried to be as realistic as possible and provided sufficed and clear information on the depicted problem. And this is because both scenarios presented depression's and schizophrenia's symptoms as outlined in the Diagnostic and Statistical Manual of Mental Disorders (DSM-IV, 1994). Moreover, Neff (1979) stated that vignettes are most productive if the scenario appears real and conceivable to respondents. I think that the vignettes used, were in accordance with Neff's criteria for productive vignettes, because there was simple wording and a realistic scenario.

Furthermore, a researcher should always have in mind that there is the risk for socially desirable responses. This study's questionnaires required no personal information, they were anonymous, and so I think that in this way I minimized this risk. There are several studies reporting that the social desirability bias is higher when people are asked directly (Finch 1987; Ganong \& Coleman, 2006; Hughes \& Huby, 2004).

Another disadvantage is that vignettes are "accused" of being very simple and not able to capture the complexity of the real world. But as Barter and Renold (2000) 
argued, vignettes are a valuable tool to use in order to deal with this complexity and focus on the studied topic.

Additionally, using vignettes as a method I didn't expect to have the same amount of in depth information as I would have with interviews. This is because I couldn't ask further questions about important and relevant issues that came out from their answers. But I didn't use interviews or a focus group because people may don't want to talk for a sensitive issue in front of others.

A last criticism against this methodology is that respondents base their answers on how they think they would respond to a similar situation and we don't know how they actually would react in real life (Potter, 1987). But from the other hand, there are researchers who support that vignettes "mirror social reality" (Renold, 2002).

Generally, using questionnaires is not that common in qualitative research, but the reason that I used this method to my study was because almost all of the studies about mental health literacy have used vignettes as data collection method and because with this kind of design I was able to obtain detailed data from a personal level from a wider sample (Patton, 1990).

\section{Validity}

This section deals with the trustworthiness of my study. One of the numerous existing definitions of validity is "the level of accountability and legitimacy that is strived through data collection, analysis and interpretation” (p.273, Onwuegbuzie \& Teddlie, 2003, referred to Gelo, Braakmann \& Benetka, 2008).

My results are subjective because I was the one who decided what was important or not for the content analysis. This is a master thesis so it wasn't possible to have another person to analyse the data and to decide together for the categories. So, the study's credibility depended on my neutrality during the analysis of data. In order to have valid results and conclusions I tried to avoid some cognitive biases during the analysis. Langemar (2008) in her book "kvalitativ forskningsmetod i psykologi" referred to some psychological phenomena that could affect a study’s results. For example I was careful with confirmation bias, which can lead us to focus on information that confirms our expectations. All researchers have usually specific thoughts before starting conducting the study, about their expectations for the results. This is why I always had in mind that it is my respondents' perspective that is being studied and I never tried to adjust my respondents' words to the categories that I might have been expected to emerge.

In order to evaluate my study's validity I used Maxwell's (1992) four categories of validity for qualitative methods. First of all, descriptive validity refers to the extent that the researcher has given a valid description of settings and events during the study's procedure. My study did not lack of descriptive validity because I was quite detailed in my data collection process about how I conducted the study and during the transcription of the questionnaires to the computer I didn't add or didn't ignore any of my respondents' words, so my material can be considered to be quite reliable. 
Generalizability or transferability in qualitative researches is used with a different meaning than in quantitative ones. Maxwell (1992) defined generalizability in qualitative studies as the extent to which the results "may be useful in making sense of similar persons or situations” (p.15). So, concerning this category of validity I think it is important that first of all I chose to have the right sample for my study. Considering the fact that my aim was to assess adolescents' mental health literacy all the respondents were students, aged 15-19. However, the findings may not be representative of all Swedish adolescents because only two English schools in Stockholm participated in the study.

Furthermore, I was quite careful when I referred to respondents' views in order to avoid possible misinterpretation (Maxwell, 1992). I could therefore say that I managed to have a satisfying level of interpretative validity based on the manner in which I handled the data. The data were analyzed using a content analysis method according to Burnard (1991) and I followed every stage suggested by authors and presented clear the results.

Maxwell (1992) also refers to explanatory validity meaning "whether there is consensus within the community concerned with the research about the terms used to characterize the phenomena” (p.14). My study's explanatory validity could not be questioned because the themes emerged from my study are in accordance with similar previous studies (Farrer et al., 2008; Jorm et al. 1997, etc). In this type of validity Maxwell also includes construct validity. Construct validity was established by using the correct operational measure, meaning reliable vignettes that addressed the research questions and that had been used previously by Jorm and his colleagues many times (1997; 2008; 2009). Moreover, the vignettes fulfilled Jergeby’s (1999) four requirements for a reliable vignette:

- It should be easy to understand

- It should be consistent.

- It should be credible.

- It should not be too complex (p. 26)

\section{Discussion of results}

The purpose of this study was to examine Swedish adolescents' mental health literacy concerning depression and schizophrenia, stigmatizing attitudes towards mentally ill, and levels of altruism. Generally, I could say that according to the results there seems to be substantial room for improvement in the area of mental health literacy. The results showed that adolescents lack knowledge of depression, schizophrenia and the appropriate help-seeking behavior. Depression and schizophrenia were not easily recognized by the teenagers and numerous incorrect explanations were given for the presented behaviors. Furthermore, respondents were more likely to prefer self-help interventions as the best type of help. It was also shown that misconceptions and low mental health literacy about schizophrenia caused stigmatizing attitudes and beliefs. 


\section{Mental health literacy about depression}

The results of the students' perceptions on depression indicated a fairly low level of mental health literacy regarding the recognition of depression. Even though there were many students who recognized depression (136), the majority of them misidentified it. This finding is confirmed by other vignette studies, which have showed adults' disability to correctly identify depression (Angermeyer, Matshinger \& Heller, 1999; Jorm, Christensen \& Griffiths, 2006; Jorm et al., 1997). In addition, the only relevant Swedish study (Dahlberg et al., 2008), which was conducted in the county of Skaraborg, found that a mental illness in the past doesn't enhance the recognition of depression. More specifically, only the one third of the participants with symptoms of mental illness could recognize depression in the vignette and they found almost the same results for the mentally healthy persons.

The categories and subcategories that emerged from the answers were similar to those found in the first study that Jorm et al. (1997) conducted on mental health literacy. In this Australian study, 2031 adults participated and 39\% of them were able to identify depression correctly. Eight other subcategories were created to include the rest of the answers. Four of them, were similar to mine: "stress","physical condition”, "has a problem” and "don't know”'. But Jorm and his colleagues found four other subcategories that I didn't include in my results and these were: "mental problems", "mental illness", "low self-esteem" and "emotional symptoms". Mental problems and some types of mental illnesses were often mentioned by my respondents too, but I don't have similar subcategories because they used these terms in order to describe depression. Regarding “self esteem”, the respondents didn't mention it at all. As an explanation for John's behavior, they were more likely to attribute this behavior to bad social relationships than to personality traits. Finally, the study by Jorm et al. doesn't make clear what the authors mean by the subcategory "emotional symptoms" so I can’t discuss this further.

Moreover, in my study there were students who did not refer to any kind of problem and a "no problem recognized" category was emerged. To my knowledge, this has not been found in other studies. This might be due to the fact that my participants were young adolescents and they were more likely to perceive John's behavior as a result of the hormone changes of puberty and thus a normal situation.

Furthermore, the same responses have also been given by Wright's et al (2005) participants (aged 12 -25 years). In this study more respondents were able to identify depression (almost 50\%) from the same vignette as presented in my study. This was also an Australian study, and the responses fit into the pre-coded categories found by Jorm et al's study (1997).

More recently, Farrer et al. (2008) conducted a vignette study in order to detect possible age differences in mental health literacy. Four age groups were examined and from the content analysis nine categories were emerged. Almost all the categories identified were similar with mine except from two of them. These categories were "cancer" and "nervous breakdown" and it was the oldest age group (+70) of the study, that referred most to these two issues so it is maybe an explanation why I didn't had similar findings from my respondents' answers. An interesting finding in Farrer et 
al.'s study was also that younger adults were more likely to misidentify depression than older adults.

Several students perceived the fictitious character described in the vignette as being stressed. But it isn't only the Swedish adolescents who conceptualized the depression vignette as stress-related. The majority of participants from a study conducted in South Africa misidentified depression as stress (Hugo et al., 2003). Moreover, many students believed that John is going through a bad phase as they mentioned and they added that it is completely normal in this age, especially if a problem came up. This finding is supported by Jorm et al. (2006) in a community survey for depression. This study also found that participants perceived depression as reaction to a personal problem that the person was too weak to handle successfully. The same results emerged from a British study (Leighton, 2010). Leighton developed a vignette based questionnaire examining adolescents' levels of mental health literacy with a mixed method approach. Her results also showed that young people tended to misidentify depression as stress. Despite the fact that $44,7 \%$ of the respondents were able to understand the problem in the depression vignette, most of respondents had "a conceptual confusion over the term depression” (p. 242). And this was because depression was not considered to be a serious mental problem. There is also another study which showed that depression is rarely recognized as a mental disorder (Lauber, Nordt, Falcato \& Rössler, 2003). Generally, it has been found that the majority of lay public is more likely to view depression as some sort of life crises than a mental disorder (Lauber, Nordt, Falcato \& Rössler, 2001).

Additionally, personal problems including bullying were often mentioned by my respondents as an explanation for John's behavior. The same views were frequently expressed in Leighton's study (2010).

It is worth mentioning that my subcategory "lack of interests" was not found in other studies mostly because the studies I examined preferred to include such explanations in other categories such as "other" or "other miscellaneous". The reason that I chose to have a different subcategory under the name of "lack of interests" was that there were a substantial number of students who referred to that in their answers.

Concerning the second question of the depression vignette "Imagine John was a friend of yours that you cared about. You want to help him. What would you do?” I coded the answers into three main categories: "formal sources of help", "informal sources of help" and "no help". The students were more likely to prefer informal sources of help, as talking which was mentioned from almost all the respondents. This is consistent with previous researches in adolescents which found that young people believe that positive support by friends is enough to help a peer in need (Dunham, 2004; Offer, Howard, Schonert \& Ostrov, 1991).

Wright et al. (2005) examined Australian adolescents' mental health literacy using the same vignettes (by Jorm et al., 1997) and they described similar categories as mine. They also found that respondents were more likely to nominate friends as best source of help. This is also in accordance with my study's results because most of the students believed that they would be able to help a depressed person for example by talking to him/her, without the help of an external source. Moreover, both in my study and in Wright' et al's (2005), general practitioners were also mentioned often from 
the respondents. Other categories that Wright et al. (2005) referred too, were “counselor/psychologist”, "social worker", "psychiatrist” and "medication” which were the same as in mine. Although medication is negatively rated by participants in some studies (Kelly, Jorm \& Rodgers, 2006; Wright et al., 2006), it is considered as helpful in others, including mine. Furthermore, two of my subcategories that were not mentioned by the authors (Wright et al., 2005) were "nurse" and "sexual intercourse" but it is possible that they included similar findings in their category "other". Moreover, the way that they cited the question concerning help seeking behavior, "How do you think John could best be helped?" maybe partly explains why a category "no help" didn't emerge in their study. In my questionnaires the question was formed this way "Imagine John was a friend of yours that you cared about. You want to help him. What would you do?", so it was easier for respondents to answer nothing if they wanted to. Moreover, it seems to be reasonable answering that way, taking into account that people often view depression as a normal life crisis (Lauber et al., 2001).

Farrer et al. (2008) preferred to code only the categories concerning a formal source of help and chose to have a category called "other" where they included various answers of the participants such as: active involvement of others, to pursue personal interests etc. Their category "other" seemed to include all my subcategories under the main category of informal sources of help. These results are also in line with findings from other studies (Burns \& Rapee, 2006; Goldney, Fisher, Dal Grande \& Taylor, 2005; Jorm et al., 1997), which found that general practitioners, counselors, friends, psychiatrists and psychologists were regarded as helpful for a person with schizophrenia.

Many respondents believed that most helpful for John would be to cheer him up and engage him in fun activities. This is in agreement with other studies (Dahlberg et al., 2008; Goldneyet et al., 2005). Moreover, respondents of several vignette studies, including mine, seemed to favor special diets and minerals (Dahlberg et al., 2008; Jorm et al., 1997). However, studies have showed that these kinds of self-helping interventions are helpful only for milder states of depression (Goldberg \& Huxley, 1992; Martinsen, 1994).

Surprisingly enough, internet was not mentioned by my respondents in the helpseeking question. Taking into account the familiarity that adolescents have with computers I expected that many respondents would choose Internet as a source of help. But it was only one student who wrote that he would choose an online forum in order to be informed and help his friend that way. This is in contrast to the results from Gould et al.'s study (2002) reporting that Internet constitutes an important helpseeking resource among adolescents.

Finally, it is worth mentioning that some of my respondents believed that sexual intercourse would be helpful for a depressed peer. According to my knowledge, there are no other studies with similar findings. I could assume that my respondents believed that this could be the best type of help because sex plays an important role in teenagers' lives as most of the people have their first sexual experience during adolescence. 


\section{Mental health literacy about schizophrenia}

Generally, as in many other studies (Farrer et al 2008; Jorm et al., 1997; Leighton, 2010) lay public's ability to recognize schizophrenia is significantly lower than their ability to recognize depression. First of all, consistent with findings from other studies (Farrer et al., 2008; Jorm et al., 1997) many students misrecognised schizophrenia as depression. No plausible explanations about this finding have been explored until .recently Farrer et al. (2008) reporting the same results, suggested that this might be due to the fact that Australia emphasized more on depression in public health programs. This assumption is not supported, because my study was conducted in Sweden whereas no public health programs have been introduced.

Moreover, the scenario presented made clear that John is not taking drugs ("They know he is not taking drugs..."), but there were still several students who believed that some sorts of drugs caused his behavior. Farrer et al. (2008) who presented the same vignettes to 3,988 participants also found that $6.4 \%$ of them indicated drug abuse.

Some of the respondents, not only in my study but also in Wright's et al. (2005) study, believed that the person with schizophrenia presented in the vignette was socially rejected, i.e. a victim of bullying. This finding is easy to understand if we take into consideration a study conducted in London about bullying victimization, by Arseneault, Bowes and Shakoor (2010). They found "a significant association between bullying and severe symptoms of mental health problems” (p. 717). Unfortunately, bullying is a reality in the schools and those who are victimized often show signs of distress and adjustment problems (Arseneault, Bowes \& Shakoor, 2010). This could explain the fact that students connected John's behavior to bullying.

Having a physical problem or other kinds of disorders were also two explanations given for John's behavior in my study, as well as to other studies. For example, two studies by Jorm et al. (1997) and Farrer et al. (2008) reported the same percentage of participants (2\%) who perceived schizophrenia as being a physical health issue.

Moreover, there were also respondents in my study who believed that nothing was wrong with John's behavior and that he was fine. This was one important difference from previous studies, as no similar results have been found in the articles reviewed. Maybe because most of the studies have used mixed methods, and answers given from a small percentage of participants were included in a category called "other". So answers indicating that nothing was wrong with the fictitious character could have been included in these categories.

Finally, there were also participants in my study who could neither correctly identify schizophrenia nor make any assumptions. They simply did not know what was wrong. Wright et al. (2005) reported that in the vignette study among Australians aged 12-25 years old, $13 \%$ of the 1207 participants indicated that they did not know what was wrong with the person described in the scenario.

With regard to help-seeking behavior students, in contrast to depression vignette, were more likely to prefer a formal source of help. This might be due to the fact that there were more respondents who could not recognize the problem depicted, than there were in the depression vignette, and when they did they reported that they would 
be scared to take care of a schizophrenic person. This is why they were more likely to choose professional help. My results do not deviate from other studies' result. Wright's et al. (2005) found that friends were more commonly, indicated by respondents as best type of help for depression while for schizophrenia, the majority of respondents recommended psychiatrists, psychologists and counselors.

Furthermore, Angermeyer, Matschinger and Heller (1999) in a German study found that while mental health professional are not considered helpful in the case of depression, they are seen as helpful in schizophrenia. Doctors on the other hand, were more frequently preferred for depression than schizophrenia (Jorm et al., 1997; Wright et al., 2005).

However, in the current study there were also findings that were inconsistent with previous research with regard to the medication and hospitalization. Although, many students in my study recommended admission to a psychiatric ward and medication as best forms of help, Jorm et al. (1997) in their study found that most of the respondents viewed these kinds of treatments as being harmful.

Finally, even though there were students in my study who reported that they would not do anything to help a friend in need, this is something not supported by other studies. But as I mentioned above this may be due to the fact that this type of answers were included in categories called "other" and no further interpretations were given.

\section{Forms of helping a peer with depression or schizophrenia}

Responses in the third open-ended question allowed me to explore adolescents' level of altruism. Fehr and Fischbacher (2003) reported in their review article that there is much individual heterogeneity concerning the altruistic behavior. This explains the fact that from the answers of 426 students 3 different categories emerged.

First of all, there were students who did not differentiate their answers to the second ("Imaging John was a friend of yours that you cared about. You want to help him. What would you do?") and the third ("Imagine John was a classmate that you did not know so well .What would you do?") help-seeking question. These answers indicated a "direct altruistic behavior" toward a mentally ill, as students were ready to help someone in need no matter how close their relation was. The social psychologist Batson in his book (The altruism question: Toward a social-psychological answer, 1991) explains why some people choose to act altruistically towards a person who is not their friend. He uses the "empathy-altruism hypothesis" to explain that one of the main reasons could be empathy: "empathic emotion evokes altruistic motivation" (p. 14).

However, most of the students reported that they would proceed to "indirect altruistic behavior", meaning that they would be willing to help, but they would rather prefer to ask someone else to do it than do something themselves. This is because many respondents reported that it would not be their responsibility to help someone they did not know that well. Moreover, they would prefer to keep a more neutral attitude because someone's health is a sensitive issue and they would not want to get actively involved. This is why they would prefer to ask a friend of his to help or his family. 
This explains Jorm's (2000) results that people with mental disorders are more likely to get professional help if relatives or friends make the contacts.

Finally, it is worth mentioning that same students who reported that they would help a friend with mental illness, in the third question (if he wasn't their friend) they made clear that they would not proceed to any kind of help-seeking behavior for this person. Either because they wouldn't feel responsible for him, or because they simply would not care for someone who isn't emotionally close to them. This finding is in line with Rachlin's and Jones' (2008) results who found a positive correlation between closeness and altruistic behavior. This means that people are more likely to exhibit altruistic behavior if with the person in need have an intimate relation. Furthermore, there is also evidence that people tend to be more altruistic towards their families and friends (Eisenberg, 1983). As mentioned in the introduction, Piliavin et al. (1981) found that "messy victims" evokes avoidance attitudes and consequently reduces altruistic motivation to help. But unfortunately, as my study shows the same happens to the "schizophrenia's victims", as well.

One other possible explanation to the no altruistic behavior in my study is given by Batson, Duncam, Ackerma, Buckley and Birtch (1981). They conducted an experiment with 44 female students and found that it is more likely for people not to help when escaping the situation is easy and it is certainly easier to ignore a peer's needs who is not your friend than someone's who is closer to you emotionally.

\section{Stigma and attitudes towards schizophrenic symptoms}

It was in the schizophrenia vignette that two manifestations of schizophrenia related stigma were revealed. In the data collected from depression vignette this was not found in any of the answers. This is in accordance with Mann and Himelein's vignette study (2004) including 116 undergraduate students' attitudes which found that schizophrenia is a mental illness linked to more stigma related attitudes than depression. Stigma related attitudes was expected to be found in my study, taking into account that young people tend to exhibit more stigmatizing behavior towards various mental disorders than adults (Stuart \& Arboleda-Florez, 2001), and similarly adolescents who are mentally ill are more likely to be victims of social stigma than adults (Thara \& Srinivasan, 2000). Generally, as Gale (2006) reported in her Phd thesis, mental disorders are associated with more stigma than physical illness.

Many students used derogatory terms to describe the person with schizophrenia. The use of this kind of words for mentally ill could be interpreted as indicator of lack of basic knowledge about schizophrenia and as evidence for the existence of strong prejudices against it. Similar results were seen in two other studies which examined students' perceptions to mentally ill. When Rose, Thornicroft Pinfold and Kassam (2007) asked students "What sorts of words or phrases might you use to describe someone who experiences mental health problems?” almost half of them used derogatory terms. Moreover, Chandra and Minkovitz (2007) conducted in depth interviews with 57 students and found that they preferred to use negative terms to describe mental illness. 
The results of students' views towards the person with schizophrenia showed that they considered him to be dangerous. The myth of the dangerous schizophrenic, which is continuously reinforced through the media (Thornicroft, 2006) was also present in my study. There are several studies reporting that schizophrenics' dangerousness is just a myth but the students seemed to be unaware of it or/and incorrectly informed. In reality, it is the schizophrenics who are in greater danger of being the victims of violence (Whalen, 2009). Moreover, an older review by Hayward and Bright (1997) highlighted the fact that schizophrenic's dangerousness is one of the main causes of stigmatizing attitudes. They also, reviewed various studies concerning stigma and they referred to a number of methodologies used each time. They concluded that open-ended and vignette methods tended to be more able to reveal negative views towards mental illnesses than other methods. So, one of the reasons that I found high levels of stigma among adolescents, could be partly due to the methodology used in this study.

High school students expressed their open rejection to a schizophrenic person by stating that they would not care for him/her and they would prefer to stay away in any case. Similar feelings of embarrassment and rejection were expressed by young participants in an Australian study about mental illness (Barney, Griffiths, Jorm \& Christensen, 2006). This attitude could be explained by Corringan's et al. (2005) study. They used the Attribution Questionnaire to adolescents, and concluded that people react with avoidance and discrimination towards mentally ill, because they attribute the responsibility to them for their health condition.

Moreover, some students reported that they would not only treat the person as a social outcast because of his "weird" behavior but they would also avoid assisting him seek help. Low mental health literacy is once again obvious and is consistent to the findings of Rose et al. (2007), who found that among young people the stigma appeared to be a substantial barrier to help seeking for mental problems. So, it is not only the mentally ill who refuse to seek help for their problems (Adams, Lee, Pritchard \& White, 2009; Mojtabai 2010; Murry, Heflinger, Suiter \& Brody, 2011), but it is also their environment that refuses to help them for the same reason, as my study showed. This was similar to Simmons' (2000) finding who revealed that $85 \%$ of children were not receiving the necessary professional help for their mental problems because of their parents' fear for stigmatization.

\section{Limitations of the study}

Every study has its limitations, which need to be identified in order to critically evaluate the results.

First of all, the findings may not be generalizable to the broader Swedish adolescent population because the sampling was limited to Sweden's capital (Stockholm) and young people's mental health literacy may vary across the country. There is one study, for example, (Griffiths, Christensen \& Jorm, 2009) which reported differences in mental health literacy between rural and urban areas. Inner city residents were more likely to be able to identify mental disorders correctly and rural residents considered alcohol and painkillers as being the best form of help for mental disorders instead of psychotherapy. 
Furthermore, the questionnaires were in English instead of Swedish, which includes the risk of limiting the respondents' language. However, the respondents used their native language when they had difficulties to express themselves in English.

Another limitation includes the fact that the respondents' written views may not translate into a common understanding of the terms used between participants and mental health professionals. In other words, a respondent who characterized the scenario's person as depressed may not have the same things in mind with a psychologist who thinks in terms of DSM-IV's definition. So, the students who referred to depression, might have perceived the term in a different way, they might have meant for example sadness, or a bad mood, and not the mental pathology (Burns \& Rapee, 2006).

Then, even though the study was anonymous, the impact of potential social desirability bias in students' responses can't be excluded. Moreover, I have described in the method section the disadvantage of using vignettes. I can't really know that the answers reflect the reactions in a real life situation. A method based on more naturalistic settings might have been better.

Finally, as already mentioned in the validity part, I was the only one who analyzed the data. However my supervisors read and approved the categories and subcategories emerged and previous studies' results were consistent to mine.

Consequently, considering the limitations, the results should be interpreted cautiously.

\section{Study’s practical implications}

This study demonstrates a quite poor mental health literacy level among students in Sweden. Schizophrenia is accompanied with a lot of stereotypes and depression is usually not recognized, or is misrecognised and considered to be something more temporary. This highlights the need for creating and promoting public awareness activities on mental health in Sweden. Increasing mental health literacy especially in young people (because the onset of mental disorders peaks during adolescence), could help minimizing the number of undiagnosed people. Awareness campaigns could contribute to change of people's beliefs and prejudices against mental disorders.

Mental health promotion in Sweden could be assessed in many ways and it should be aimed at:

-Raising the awareness in community healthcare professionals and in the public about prevention, symptoms and treatment of mental disorders.

-Educating both students and teachers about the existing mental health institutions or counseling centers in their area.

- Reducing stigma that surrounds most of the mental illnesses, such as depression and schizophrenia, to a bigger extent, by eliminating misconceptions and myths.

There are numerous ways of achieving these goals. Sharing flyers at schools is a quite easy and cheap way for providing general information about psychological health. It 
is important to include information about the diagnosis, how mental problems affect one's life, symptoms and treatment. Moreover, it will help students realize that human beings are psychophysiologic organisms, which can be affected by both physical and mental problems.

I also think that psychoeducation, which could easily be integrated in schools in form of courses could help students to learn more in order to better handle depression and schizophrenia whether it is a personal problem or if it is affecting someone in the close environment. Educating students and teachers on mental health issues will be a facilitating factor for adolescents, as it will improve their relations with their classmates dealing with similar problems. The educational system can strengthen students' mental health awareness in many ways, through relevant educational films, suggesting books etc.

In addition, applying various practices in order to enhance mental health literacy will possibly help reducing stereotypes, which are extensively promoted by media. I think that we all have watched a movie with a schizophrenic killer, at least once in our lives. Unfortunately, this is the way that media generally, refer to these people, so the myth of the dangerous psychopath is not only maintained but also reinforced. Involving mass media (including TV, radio, magazines and newspapers) in an awareness campaign would be one of the most effective interventions considering the number of people that have daily access to them.

Finally, from my own experience, I think that students' personal contact with mental health consumers is necessary. Few years ago, I had the opportunity to work and live with people diagnosed as schizophrenics in Crete, through a European program aiming to improve mentally ills' daily live. I have to say, that I have never been prejudiced against any type of mental illness and I have read a lot about this topic, but having the chance to hear these people's personal stories and view of their disorder gave me the opportunity to understand this mental illness from another aspect, a different one from this that psychiatrists and DSM-IV gives, a more humanistic one. So, it would be very useful conducting a program whereas mentally ill can speak in classrooms about their experience or even students visiting them.

All the above, could provide personal and social benefits by an early detection of students with mental health problems and thus an opportunity for early intervention and treatment.

I'm aware of course, of the big cost that all these mental health literacy programs would require but taking into account the large amounts of money spent worldwide on treatment it wouldn't be unreasonable to invest little more on prevention and awareness campaigns. Especially, if we bear in mind that there are strong evidence of effectiveness of similar programs that have been conducted in Australia, Canada, United states and Norway "in terms of improvements in knowledge and attitudes" towards depression and schizophrenia (p.7, Francis, Pirkis, Dunt, Blood \& Davis, 2002). So, similar positive results could most certainly be expected in Sweden. 


\section{Future research}

The purpose of this study has been mental health literacy and levels of altruism in help-seeking behavior among adolescents in Stockholm. In contrast to Australia, Sweden has not examined these issues to a great extent. This is a master thesis so I could neither have a bigger sample nor use a mixed method, which would have enabled me to have more interesting and valuable results. Future research could utilize a larger sample and mixed methods, which will allow more accurate analyses and would give a better understanding of lay public's mental health literacy. Specific research questions in order to fill the existing research gap in Sweden concerning mental health literacy, deserve further evaluation, such as follows:

-Do individual characteristics influence the ability of public to recognize schizophrenia and depression? For this reason, more information about the participants' background should be included. Topics of interest could be for example whether gender or cultural background influence people's beliefs about mental illnesses and their treatment.

-Do adults have a better understanding of mental disorders and best forms of treatment? Investigating and comparing various age groups could help us finding it out.

-Should we expect different results and poorer mental health literacy from Swedish rural areas? More research should be conducted in various regions of Sweden to explore potential disparities between rural and urban areas.

-What is adolescents' reaction to a peer in need in real life? Bearing in mind that most of the studies about mental health literacy have applied the vignette method and are qualitative in nature it would be interesting to explore this issue with another method or to conduct a study, which would have as sample criterion respondents' previous relevant experience.

\section{List of references}

Adams, E. F., Lee, A. J., Pritchard, C. W., White, R. J. (2010). What stops us from healing the healers: a survey of help-seeking behaviour, stigmatisation and depression within the medical profession. International Journal of Social Psychiatry. 56, 359-70.

American Psychiatric Association. (1994). Diagnostic and Statistical Manual of Mental Disorders. (Fourth Edition Text Revision). Washington: American Psychiatric Association.

Angermeyer, M. C, Matschinger H., \& Riedel-Heller S. G. (1999). Whom to ask for help in case of mental disorder? Preferences of the lay public. Social Psychiatry and Epidemiology, 34, 202-210.

Arseneault, L., Bowes, L., Shakoor, S. (2010). Bullying victimization in youths and mental health problems: 'much ado about nothing'? Psychological Medicine, 40, 717-29.

Australian Bureau of Statistics . (2006). National Health Survey: summary of results 2004-2005 . Canberra, Australia: Government Publishing Services. 
Bagley, H., Cordingley, L., Burns, A., Mozley, C. G., Sutcliffe, C., Challis, D., Huxley, P. (2000). Recognition of depression by staff in nursing and residential homes , Journal of Clinical Nursing ,9, 445-450.

Bailey, S. (1999). Young people, mental illness, and stigmatization. Psychiatric Bulletin, 23, 107-110.

Barney, L. J., Griffiths, K. M., Jorm A. F., Christensen, H. (2006). Stigma about depression and its impact on help-seeking intentions. Australian and New Zealand Journal of Psychiatry, 40, 51-54.

Barter, C., \& Renold, E. (2000). I wanna tell you a story: exploring the application of vignettes in qualitative research with children and young people. International Journal of Social Research methodology, 3, 307-323.

Batson, C., D. (1991). The Altruism Question: Toward a Social-Psychological Answer. Lawrence Erlbaum Associates.

Batson, C. D., Duncan, B., Ackerman, P., Buckley, T., \& Birch, K. (1981). Is empathic emotion a source of altruistic motivation? Journal of Personality and Social Psychology, 40, 290-302.

Bourget, B. \& Chenier, R. (2007). Mental Health Literacy in Canada: Phase One Report Mental Health Literacy Project. Canadian Alliance on Mental illness and Mental Health.

Bourget Management Consulting (2004). Mental Health Literacy: A Review of the Literature. The Canadian Alliance on Mental Illness and Mental Health.

Burke, K. C., Burke, J. D., Regier, D. A., Rae, D. S. (1990). Age at onset of selected mental disorders in five community populations. Archives of General Psychiatry, 47, 511-518.

Burnard, P. (1991). A method of analysing interview transcripts in qualitative research. Nurse Education Today, 11, 461-466.

Burns, J. R., Rapee, R. M. (2006) Adolescent mental health literacy: Young people's knowledge of depression and help seeking. Journal of Adolescence, 29, 225-239.

Byrne, P. (1997). Psychiatric stigma the past, passing and to come. Journal of Royal Society of Medicine, 90, 618-621.

Caldwell, T. M. \& Jorm, A. F. (2000). Mental health nurses’ beliefs about interventions for schizophrenia and depression: a comparison with psychiatrists and the public. Australian and New Zealand Journal of Psychiatry, 34, 602-611.

Chandra, A. \& Minkovitz, C. S. (2007). Factors that influence mental health stigma among 8th grade adolescent. Journal of Youth and Adolescence, 36, 763-774.

Corrigan, P. W., Lurie, B. D., Goldman, H. H., Slopen, N., Medasani, K., Phelan, S.(2005). How adolescents perceive the stigma of mental illness and alcohol abuse. Psychiatric Services, 56, 544-550.

Dahlberg, K. M., Waern, M., Runeson, B. (2008). Mental health literacy and attitudes in a Swedish community sample -investigating the role of personal experience of mental health care. BioMedCentral public health, 8: 8.

Department of Child and Adolescent Health and Development (2007).

Adolescents, social support and help-seeking behaviour : an international literature review and programme consultation with recommendations for action . Geneva, Switzerland: World Health Organization.

Dirway, N. P. (2002) Mental illness in primary health care :A study to investigate nurse's knowledge of mental illness and attitudes of nurses toward the mentally ill. (Unpublished Master Thesis). University of Cape town . 
Dunham, K. (2004). Young adults' support strategies when peers disclose suicidal intention. Suicide and Life Threating Behavior, 34, 56-65.

Eccles, J. S., \& Barber, B. L. (1999). Student council, volunteering, basketball, or marching band: What kind of extracurricular involvement matters? Journal of Adolescent Research, 14, 10-43.

Eisenberg, N. (1983). Children's differentiations among potential recipients of aid. Child Development, 54, 594-602.

Evidensbaserad omvårdnad - Behandling av personer med schizofreni. (2009). Accessed April 2011 from http://www.sbu.se/upload/Publikationer/Content0/2/omvardnad_schizofreni/omvschizofull.html

Farrer, L., Leach, L., Griffiths, M. K., Christensen, H., \& Jorm, A. F. (2008).

Age differences in mental health literacy. BioMedCentral Public Health 8:125.

Fehr, E. \& Fischbacher, U. (2003). The nature of human altruism. Nature, 425, 785 - 791.

Finch, J. (1987). The vignette technique in survey research. Sociology, 21, 105-114.

Fisher, L. J., Goldney, R. D. (2003). Differences in community mental health literacy in older and younger Australians. International Journal of Geriatric Psychiatry., 18, 33-40.

Francis, C., Pirkis, J., Dunt., D., Blood, R.W., Davis, C. (2002). Improving mental health literacy: a review of the literature. Melbourne \& Canberra: Centre for Health Program Evaluation.

Fredrickson, B. L. (2003). The value of positive emotions: The emerging science of positive psychology is coming to understand why it's good to feel good. American Scientist, 91, 330-335.

Ganong, L. H., \& Coleman, M. (2006). Multiple segment factorial vignette designs. Journal of Marriage and Family, 68, 455-468.

Ganasen, K. A., Parker, S., Hugo, D. J., Stein, D. J., Emsley, R. A., Seedat , S. (2008). Mental health literacy: focus on developing countries. African journal of psychiatry, 11, 23-28.

Gale, F. (2006). Children's and parents'/carers' perceptions of mental health and stigma. Unpublished PhD thesis, University of Leicester.

Gelo, O., Braakman, D., Benetka, G., (2008). Quantitative and qualitative research beyond the debate , Integrative Psychological and Behavavioral Science, 42, 266-290.

Gifford-May, D. (2002). Adolescents' knowledge and beliefs about depression, coping strategies and barriers to help-seeking: Gender and ethnic differences.(Unpublished Master's Thesis). Macquarie University.

Goldberg, D. \& Huxley, P. (1992). Common Mental Disorders: A Bio-Social Model. London \& New York: Routledge.

Goldney, R. D., Fisher L. G., Dal Grande, E., Taylor, W. (2005). Changes in mental health literacy about depression : south Australia 1998 to 2004. The Medical Journal of Australia, 183, 134-137.

Goldney, R. D., Fisher, L. J., \& Wilson, D. H. (2001). Mental health literacy: An impediment to the optimum treatment of major depression in the community. Journal of Affective Disorders, 64, 277-284.

Gould, M. S., Munfakh, J. L. H., Lubell, K., Kleinman, M., \& Parker, S. (2002). Seeking help from the Internet during adolescence. Journal of the American Academy of Child and Adolescent Psychiatry, 41, 1182-1189.

Griffiths, K. .M., Christensen, H., Jorm, A. (2009). Mental health literacy as a function of remoteness of residence :an Australian national study. BioMedCentral public health, 9, DOI: 10.1186/1471-24589-92. 
Hayward, P. \& Bright, J. A. (1997). Stigma and Mental Illness. A Review and Critique. Journal of Mental Health, 6. 345-354.

Hickie, I. (2004). Reducing the burden of depression: are we making progress in Australia?. The Medical journal of Australia, 181, 4-5.

Hughes, R. (1998). Considering the vignette technique and its application to a study of drug injecting and HIV risk and safer behaviour. Sociology of Health and Illness, 20, 381-400.

Hughes, R., \& Huby, M. (2004). The construction and interpretation of vignettes in social research. Social Work and Social Sciences Review, 11, 36-51.

Hugo, C. J., Boshoff, D., Traut, A., Zungu-Dirwayi, N., Stein, D. J. (2003). Community attitudes toward and knowledge of mental illness in South Africa. Social Psychiatry and Psychiatric Epidemiology, 38, 715-719.

Jergeby, U. (1999). Att bedöma en social situation - tillämpning av vinjettmetoden. Stockholm: Norstedts.

Jorm, A. F. (2000). Mental health literacy: public knowledge and beliefs about mental disorders. The British Journal of Psychiatry, 177, 396-401.

Jorm, A. F., Blewitt, K. A., Griffiths, K. M., Kitchener, K. M., \& Parslow, R. (2005). Mental health first aid responses of the public: Results from an Australian national survey. BioMedCentral Psychiatry, 5, 9.

Jorm, A. F., Kelly, C. M., Wright, A., Parslow, R.A., Harris, M.G., \& McGorry, P.D. (2006). Belief in dealing with depression alone: Results from community surveys of adolescents and adults. Journal of Affective Disorders, 96, 59-65.

Jorm, A. F., Korten, A. E., Jacomb, P. A., Christensen, H., Rodgers, B., \& Pollitt, P. (1997). Mental Health Literacy: A survey of the public's ability to recognise mental health disorders and their beliefs about the effectiveness of treatment. Medical Journal of Australia, 166, 182-186.

Jorm, A. F., Wright A. (2007). Beliefs of young people and their parents about the effectiveness of interventions for mental disorders. Australian and New Zealand Journal of Psychiatry, 41, 656-666.

Kabir, M., Iliyasu, Z., Abubakar, I. S., Aliyu, M. H. (2004). Perception and beliefs about mental illness among adults in Karfi village, northern Nigeria. BioMedCentral International Health and Human Rights, 4: 3.

Karim, S., Saeed, K., Rana, M. H., Mubbashar, M. H., Jenkins, R. (2004). Pakistan mental health country profile. International Review of Psychiatry, 16, 83-92.

Kelly, C. M., Jorm’ A. F., Rodgers' P. (2006). Adolescents’ responses to peers with depression or conduct disorder. Australian and new Zealand Journal of Psychiatry, 40, 63-66.

Kelly, C. M., Jorm, A. F., Wright, A. (2007). Improving mental health literacy as a strategy to facilitate early intervention for mental disorders. Medical Journal of Australia, 187, 26-30.

Kerr, B., Godfrey-Smith, B. \& Feldman, M. W. (2004). What is altruism?. Ecology and Evolution , 19, 135-140.

Langemar, P. (2008). Kvalitativ förskningsmetod i psykologi- att låta en värld öppna sig. Limber AB Stockholm.

Lauber C., Nordt C., Falcato L., Rössler W. (2001). Lay recommendations on how to treat mental disorders. Social Psychiatry Psychiatric Epidemiology, 36, 553-556. 
Lauber, C., Nordt, C., Falcato, L., \& Rössler, W. (2003). Do people recognise mental illness? Factors influencing mental health literacy. European Archives of Psychiatry and Clinical Neuroscience, 5, 248-251.

Leighton, S. (2010). Using a vignette-based questionnaire to explore adolescents' understanding of mental health issues. Clinical Child Psychology and Psychiatry, 15, 231 - 250.

Magliano, L., Fiorillo, A., De Rosa C., Malangone C., Maj M.(2004). Beliefs about schizophrenia in Italy: a comparative nationwide survey of the general public, mental health professionals, and patients' relatives. Canadian Journal of Psychiatry, 49, 322-30.

Mann, C. E. \& Himelein, M. J. (2004). American Psychiatric Association Factors Associated With Stigmatization of Persons With Mental Illness. Psychiatric Services, 55, 185-187.

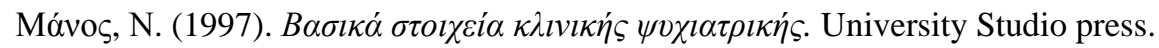

Martinsen, E. W. (1994). Physical activity and depression: clinical experience. Acta Psychiatrica Scandinavica, 377, 23-27.

Mc Kinlay, J. B. (1972). Some approaches and problems in the study of the use of services-an overview Journal of Health and Social Behavior, 13, 115-152.

Mojtabai, R. (2010). Mental illness stigma and willingness to seek mental health care in the European Union. Soc Psychiatry Psychiatric Epidemiology, 45, 705-712.

Musick, M. A., \& Wilson, J. (2003). Volunteering and depression: The role of psychological and social resources in different age groups. Social Science \& Medicine, 56, 259-269.

Neff, J. A. (1979). Interaction verses hypothetical others: the use of vignettes in attitude research. Sociology and Social Research, 64, 105-125.

Offer, D., Howard, K. I., Schonert, K. A., Ostrov, E. (1991). To whom do adolescents turn for help? Differences between disturbed and nondisturbed adolescents. Journal of the American Academy of Child and Adolescent Psychiatry, 30, 623-630.

O'Reilly, Claire, L., Bell, J., Chen, S., Timothy F. (2010). Pharmacists' beliefs about treatments and outcomes of mental disorders: a mental health literacy survey. Australian \& New Zealand Journal of Psychiatry, 44, 1089-1096.

Patton, M., Q. (2002). Qualitative research \& evaluation methods (Third Edition). Sage publications.

Piliavin, J., Dovidio, J., Gaertner, S., \& Clark, R. D. (1981). Emergency interventions. New York: Academic Press.

Potter, J., \& Wetherell, M. (1987). Discourse and Social Psychology: Beyond Attitudes and Behaviour. Sage Publications.

Paykel, E. S., \& Priest, R. G. (1992). Recognition and management of depression in general practice: Consensus statement. British, Medical Journal, 305, 1198-1202.

Post, S. G. (2005). Altruism, Happiness, and Health: It’s Good to Be Good International Journal of Behavioral Medicine , 2, 66-77.

Rachlin, H., Jones, B. A. (2008). Altruism among relatives and non-relatives. Behavioral processes, 79, 120-123.

Renold, E. (2002 ). Using vignettes in qualitative research . Building research capacity, 3, 1-12.

Rose, D., Thornicroft G., Pinfold V., \& Kassam A. (2007). 250 labels used to stigmatise people with mental illness. BMC Health Services http://www.biomedcentral.com/1472-6963/7/97 
Schwartz, C., Meisenhelder, J. B., Ma, Y., Reed, G. (2003). Altruistic social interest behaviors are associated with better mental health. Psychosomatic Medicine, 65, 778-785.

Simmons, J. (2000). Kid’s mental health tackled. Counseling Today, 15, 1-26.

Stuart, H., Arboleda-Florez, J. (2001). Community attitudes toward people with schizophrenia. Canadian Journal of Psychiatry, 46, 245-252.

Swami, V., Furnham, A., Kannan, K., Sinniah, D. (2008). Beliefs about schizophrenia and its treatment in Kota Kinabalu, Malaysia. International Journal of Social Psychiatry, 54, 164-179.

Taylor, J., Turner, R. J. (2001). A longitudinal study of the role and significance of mattering to others for depressive symptoms. Journal of Health and Social Behaviour, 42, 310-325.

Thara, R., Srinivasan, T. N. (2000). How stigmatising is schizophrenia in India? International Journal of Social Psychiatry, 46, 135-141.

Thornicroft, G. (2006) Shunned: Discrimination against People with Mental Illness Oxford, Oxford University Press.

U.S. Department of Health and Human Services (2001). Mental Health: Culture, Race, and EthnicityA Supplement to Mental Health: A Report of the Surgeon General. Rockville, MD: U.S. Department of Health and Human Services, Substance Abuse and Mental Health Services Administration, Center for Mental Health Services.

Wahl, O. F, Harman, C. R. (1989). Family views of stigma. Schizophrenia Bulletin, 15, 131-139.

Warneken, F. \& Michael Tomasello M. (2009). The roots of human altruism ,Felix British Journal of Psychology, 100, 455-471.

Whalen, D. The Stigma Associated with Mental Illness. Accessed February 2011, from http://www.cmhanl.ca/pdf/Stigma.pdf.

World Health Organization. (2001). What are Mental Health Problems.

World Health Organization. (2004). The world health report 2004.

World Health Organization. (2007). Adolescents, social support and help seeking behavior. Brazil: Instituto Promundo

Wink, P., \& Dillon, M. (2007). Do generative adolescents become healthy older adults? In S. G. Post (Ed.), Altruism \& health (p. 43-55). New York: Oxford.

Wilks, T. (2004). The Use of Vignettes in Qualitative Research into Social Work Values. Qualitative Social Work, 3: 7.

Wright, A., McGorry, P. D., Harris, M. G., Jorm, A. F., Pennell, K.. (2006). Development and evaluation of a youth mental health community awareness campaign - The Compass Strategy. BioMedCentral Public Health, 6, 215.

Yeo, S. G., Parker, G., Mahendran, R., Jorm, A. F., Yap, H. L., Lee C., et al. (2001). Mental health literacy survey of psychiatrically and generally trained nurses employed in a Singapore psychiatric hospital. International Journal of Nursing Practice, 7, 414-21.

Young, K. (1997). Research and consultation among young people on mental health issues. Final report. Canberra: Australian Government Department of Health and Family Services. 


\title{
APPENDICES
}

\author{
Appendix 1: Information to the Teacher/Mentor
}

\section{Information to the Teacher}

\section{Important:}

In order not to influence the students' perceptions and answers, and thus the study's results, do NOT share any of this information with the students before they have completed the questionnaire.

This investigation is done in order to find out how well teenagers recognize depressive and psychotic disorders and what they think one should do in such situations.

Depression is a very common illness that is treatable. Many studies have shown that less than half of those who get affected seek help. We do not know whether this is because they don't recognize the illness or because they perceive health care in a negative way.

Psychosis, on the other hand, is a less common mental illness but much more stigmatizing. Even in such cases it is very important with early treatment and support.

\section{Instructions-}

- Hand out the vignettes to all students.

- Let the students read through the instructions by themselves and do NOT give any information about the study's nature and aims.

- After the students have finished writing collect the vignettes.

- If students have further questions, encourage them to contact the study's supervisors (contact details are given on the "Answer" sheet).

- For documentation and statistical reasons please fill in the spaces below and include this page together with the completed questionnaires:

Name of the school:

Name of the class: 
Name of the supervising teacher/mentor:

Number of students in the class:

Number of students who participated:

Thank You! 


\section{Appendix 2: Vignette}

Gender: $\quad$ a. Male b. Female

$\begin{array}{llllll}\text { Age: } & \text { a. } 15 & \text { b. } 16 & \text { c. } 17 & \text { d. } 18 & \text { e. } 19\end{array}$

Education: a. Natural Science Program b. Social Science Program

c. Arts/Aesthetic Program

\section{$\underline{\text { Instructions }}$}

Please read the following two cases about John, 17 years old.

Answer shortly to the questions with your personal opinion.

Feel free to write exactly what you think.

Your answers are anonymous and your participation voluntary.

\section{Case I}

John is 17 years old. He has been feeling unusually sad and miserable for the last few weeks. Nothing special has happened the weeks before so he does not understand why. Even though he is tired all the time, he has trouble sleeping nearly every night. John doesn't feel like eating and has lost weight. He has difficulties in concentrating in school and his results are less good.

Is everything fine with John? If not, what would you say is wrong with him?

If you thought that something is wrong with John, continue and answer the following questions: 
Imagine John was a friend of yours that you cared about. You want to help him. What would you do?

Imagine John was a classmate that you did not know so well. What would you do?

\section{$\underline{\text { Case II }}$}

John is 17 and lives home with his parents. Over the last months he has stopped seeing his friends and going to school. He spends most of his time in his room and does not even sit by the computer in the hall. His parents also hear him walking around his bedroom at night while they are in bed. Even though they know he is alone, they have heard him talking as if someone else is there. When they try to encourage him to do more things outdoors, he whispers that he won't leave home because the neighbor is spying upon him. They know he is not taking drugs because he never sees anyone or goes anywhere.

Is everything fine with John? If not, what would you say is wrong with him?

If you thought that something is wrong with John, continue and answer the following questions:

Imagine John was a friend of yours that you cared about. You want to help him. What would you do? 
Imagine John was a classmate that you did not know so well. What would you do?

\section{Thank you for your participation!}




\section{Appendix 3: Answer Sheets}

\section{Answers}

\section{$\underline{\text { Case I }}$}

John is 17 years old. He has been feeling unusually sad and miserable for the last few weeks. Nothing special has happened the weeks before so he does not understand why. Even though he is tired all the time, he has trouble sleeping nearly every night. John doesn't feel like eating and has lost weight. He has difficulties in concentrating in school and his results are less good.

John has probably been affected by a depression. This can be cured. John could go to a general practitioner or a psychiatrist for example. He can receive treatment like psychotherapyand/or antidepressants.

\section{Case II}

John is 17 and lives home with his parents. Over the last months he has stopped seeing his friends and going to school. He spends most of his time in his room and does not even sit by the computer in the hall. His parents also hear him walking around his bedroom at night while they are in bed. Even though they know he is alone, they have heard him talking as if someone else is there. When they try to encourage him to do more things outdoors, he whispers that he won't leave home because the neighbor is spying on him. They know he is not taking drugs because he never sees anyone or goes anywhere.

John has probably been affected by Schizophrenia. This is a psychotic disorder that needs to be treated within the psychiatric care. He needs to be treated by a team of professionals. The type of support and pharmacological treatment that is necessary is decided after a careful examination has been done. Many persons get completely recovered while others will have a few symptoms left but still live a normal life. To reduce the risk for relapse, regular contact with psychiatric care is necessary. If you suspect someone has been affected by psychosis you can contact a psychiatric open care unit or a general practitioner for advice.

\section{If you have questions or need more information feel free to contact the study's coordinators:}




\section{Yvonne Forsell}

MD, Associate Professor

Yvonne.Forsell@ki.se

Phone: +4687373850

Dep. Public Health, Div. Social Medicine

Norrbacka, Karolinska Hospital

\section{Philippe Melas}

PhD candidate

Philippe.Melas@ki.se

Solna, Karolinska Institute 
Appendix 4: Tables

Table 1. Participant information $(N=426$, Age mean $=16.1$; Age range $=15-19)$

Number of participants Percentage

\begin{tabular}{lll}
\hline Gender & & \\
\hline Males & 154 & $36.1 \%$ \\
Females & 265 & $62.2 \%$ \\
Unkwown gender & 7 & $1.6 \%$ \\
& & \\
\hline Educational Program & & $50 \%$ \\
\hline Natural science & 213 & $43.8 \%$ \\
Social science & 187 & $6.1 \%$ \\
Unknown/Other program & 26 & \\
\hline
\end{tabular}

Table 2. Mental health literacy about depression

\begin{tabular}{lll}
\hline Recognition & Misrecognition & No problem recognised \\
\hline & Stress & \\
Personal problems & \\
Physical problems & \\
Lack of interests & \\
Unidentified problems &
\end{tabular}

Table 3. Forms of helping a friend with depression

\begin{tabular}{|c|c|c|}
\hline Informal sources of help & Formal sources of help & No help \\
\hline Personal communication & General practitioners & \\
\hline Relaxation \& entertainment & School counselors \& nur & \\
\hline Nutrients \& sleep & Social workers \& therapi & \\
\hline Adult help & Psychologists & \\
\hline Being supportive & Psychiatrists \& medicati & \\
\hline
\end{tabular}


Table 4. Mental health literacy about schizophrenia

\begin{tabular}{lll}
\hline Recognition & Misrecognition & No problem recognised \\
\hline & Social isolation & \\
Social rejection & Insecurity \\
& Other disorders & \\
Drugs & Unidentified problem
\end{tabular}

Table 5. Forms of helping a friend with schizophrenia

\begin{tabular}{|c|c|c|}
\hline Informal sources of help & Formal sources of help & No help \\
\hline $\begin{array}{l}\text { Personal communication } \\
\text { Adult help } \\
\text { Entertainment }\end{array}$ & $\begin{array}{l}\text { General practitioners } \\
\text { Psychologists } \\
\text { Psychiatrists } \\
\text { Therapists \& counselors } \\
\text { Other professional help } \\
\text { Hospital } \\
\text { Medication }\end{array}$ & \\
\hline
\end{tabular}

Table 6. Forms of helping a peer with depression or schizophrenia

\begin{tabular}{lcl}
\hline Direct altruistic behavior & Indirect altruistic behavior & Non altruistic behavior \\
\hline Personal communication & Friends & Indifference \\
Professional help & Family & Discreetness
\end{tabular}

Table 7. Stigma \& attitudes towards schizophrenic symptoms

Forms of stigma

Fearfulness

Rejection 